\title{
젊은 산개성단 M29 (NGC 6913) 영역의 변광성 VARIABLE STARS IN THE REGION OF AN YOUNG OPEN CLUSTER M29 (NGC 6913)
}

\author{
전영범 \\ 한국천문연구원 \\ YOUNG-BEOM JEON \\ Korea Astronomy and Space Science Institute \\ E-mail: ybjeon@kasi.re.kr \\ (Received October 29, 2009; Accepted November 23, 2009)
}

\begin{abstract}
From the short-period variability survey (SPVS) in Bohyunsan Optical Astronomy Observatory, I obtained time-series $B V$ CCD images in the region of the young open cluster M29 (NGC 6913) for 15 nights from May 30, 2008 to September 17, 2009. I observed 48 variable stars including 45 new ones. They consisted of $5 \delta$ Scuti, a Cepheid, 16 eclipsing binaries and 24 semi-long periodic and/or slow irregular type variable stars including $\beta$ Cephei and LPB type stars. For the rest two ones, the type of variability was not defined. I also checked the variability of the 26 known variable stars listed in the GCVS. Only three ones among 26 known variable stars confirmed variability.
\end{abstract}

key words: clusters: — M29; NGC 6913, stars: variables $-\delta$ Scuti; Eclipsing binaries

\section{1. 서론}

이 연구는 2005년부터 지속적으로 수행해 오고 있는 보 현산천문대의 단주기 변광성탐사 연구 (SPVS)는 지금 까지 10 여개의 산개성단 및 임의의 영역에 대해 수행 해 왔다 (Jeon et al. 2005a, 2005b, 2007; Jeon 2008). 주된 탐사 영역은 산개성단이지만 실제로는 중심부에 산개성단을 포함한 $1.0^{\circ} \times 1.5^{\circ}$ 의 넓은 영역을 포함하 므로 많은 변광성이 성단 구성원이 아닌 주변에서 발 견되고 있다.

젊은 산개성단 $\mathrm{M} 29$ (NGC 6913)는 $\mathrm{WEBDA}^{1}$ 에 따 르면 시직경이 약 $10^{\prime}$ 이며, 적경 $20^{h} 23^{m} 57^{s}$, 적위 $38^{\circ} 30^{\prime} 30^{\prime \prime}$ 이며, 은하면 $\left(b=0.6^{\circ}\right)$ 상의 Cygnus OB1 성협에 놓여있다. 또한 거리지수 $10.3 \mathrm{mag}$, 성간소광량 0.744 로서 $1.1 \mathrm{kpc}$ 의 거리에 위치하고 있다. 이 성단의 나이는 WEBDA 에서는 $12 \mathrm{Myr}$ 로 나와 있으나 Joshi et al. (1983)에 따르면 0.3 에서 $1.75 \mathrm{Myr}$ 로 아주 젊은 성단이다. 이 성단의 알려진 각 크기는 대략 $10^{\prime}$ 이며, 중심부의 밝은 별들은 SPVS (Short-Period Variability Survey; Jeon et al. 2005a, 2007) 의 대상으로는 너무 밝아서 이들의 변광 특성은 $B$ 필터에 의해 변광 여부만 확인할 수 있었다.

이 성단에 대한 변광성 관측 연구는 $\mathrm{Kim} \& \mathrm{Lee}$ (1996), Boeche et al. (2004)등에 의해 4개의 변광성

\footnotetext{
${ }^{1}$ http://www.univie.ac.at/webda/
}

이 알려져 있다. 또한 전체 관측 영역에 대해 $\mathrm{GCVS}^{2}$ (Samus et al. 2004)에는 26개의 변광성이 수록되어 있 으나 대부분 변광여부가 불확실하여 이 연구가 M29를 중심으로 $1.0^{\circ} \times 1.5^{\circ}$ 의 넓은 영역에 대한 체계적인 첫 변광성 탐사가 될 것이다.

2 절에서는 관측 및 분석을 정리하였고, 3 절에 그 결 과를, 그리고 마지막 절에 전체결과의 요약 및 검토가 이루어졌다.

\section{2. 관측 및 분석}

젊은 산개성단 $\mathrm{M} 29$ 영역에 대한 관측은 2008 년 5 월 30 일부터 2009년 9월 17 일 사이에 $B V$ 필터로 15 일간 이루어졌다. 노출시간은 $B V$ 필터에 대해 2008년에는 각각 150 초, 2009 년에는 각각 200 초이다. 이 관측은 SPVS 관측의 일환으로 이루어졌으며, 구경 $155 \mathrm{~mm}$ 의 소형 굴절망원경과 $2048 \times 3072$ 소자를 가지고 있는 전기 냉각 방식의 Apogee 사 AP9E CCD 카메라를 사 용하였다. 전체 관측영역은 $1.0^{\circ} \times 1.5^{\circ}$ 이다. 관측 시 스템에 대한 자세한 설명은 Jeon et al. (2005a, 2007)에 있다. 2008년부터는 자동추적장치의 원활한 작동으로 노출시간을 200 초 이상으로 증가시켜도 무리없이 관측 이 이루어지고 있다.

그림 1 은 $V$ 영상 중 하나이며, 48 개의 관측된 변광

\footnotetext{
${ }^{2}$ http://www.sai.msu.su/groups/cluster/gcvs/gcvs/
} 


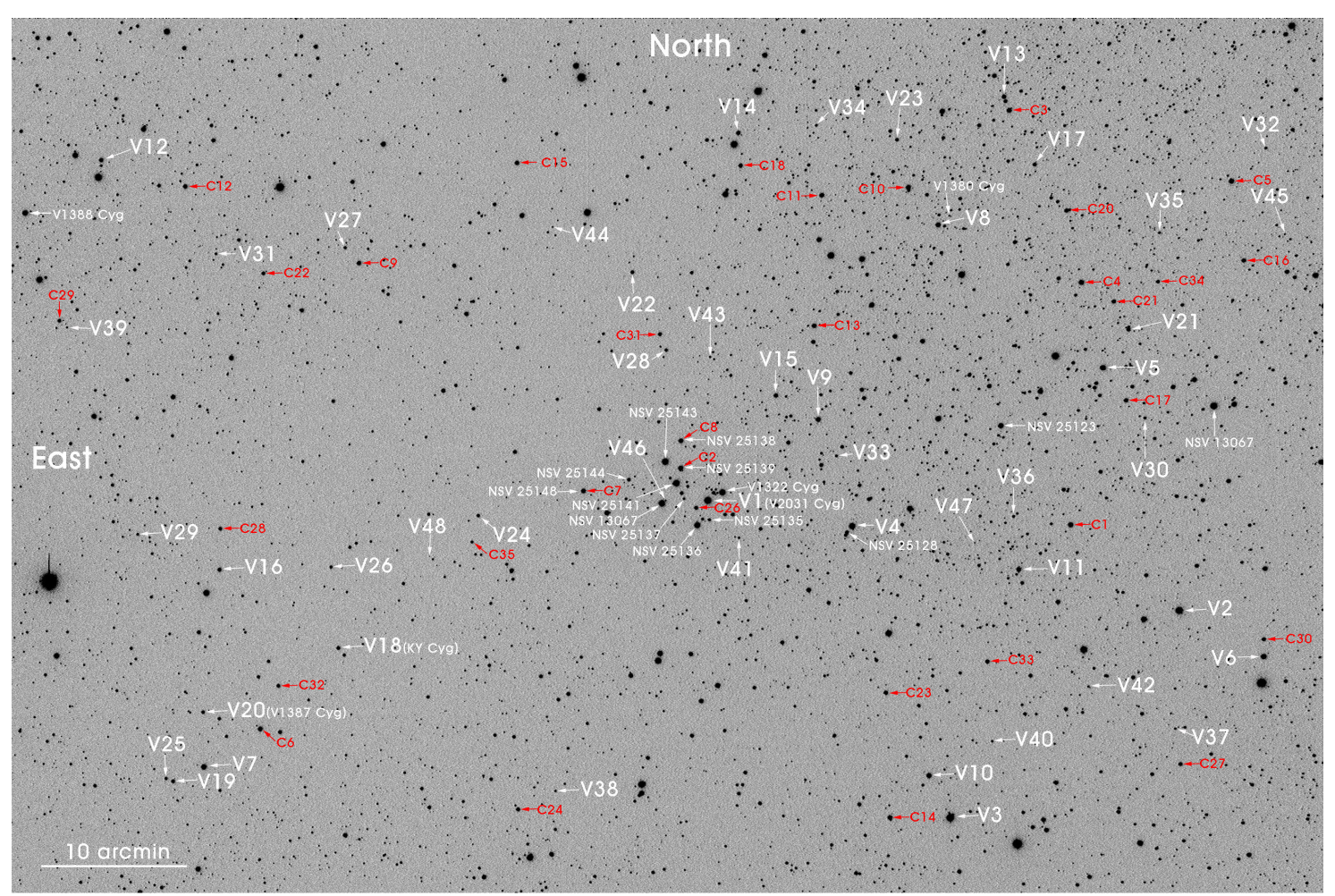

그림 1.- M29 영역에서 관측된 변광성의 분포도. 이 연구에서 구한 변광성은 V1에서 V48까지 큰 글자로, 비교성은 $\mathrm{C} 1$ 에서 $\mathrm{C} 35$ 까지 작은 글자로 나타내었다. 그 위의 이름은 $\mathrm{GCVS}$ 에 올라있는 변광성들 중 확인이 된 것들이다.

성 (V1부터 V48까지)과 GCVS 에 수록된 26개의 알려 진 변광성을 나타내었다. 또한 35 개의 비교성 $(\mathrm{C} 1$ 부터 $\mathrm{C} 35$ 까지)도 같이 표시하였다. 각각의 변광성은 각 변 광성에 가급적 가까이 위치한 별 중에서 밝고 밝기 변 화가 없는 별을 비교성으로 택하여 차등측광이 이루어 졌다. 각각의 비교성은 차등측광 이전에 밝기 변화를 세밀하게 조사하였다. 실제 사용된 비교성은 표1의 두 번째 칸에 수록하였다.

관측된 $\mathrm{CCD}$ 영상자료는 IRAF/CCDRED (Stetson 1987, Massey \& Davis 1992)를 이용하여 영점보정, 암 잡음보정, 플랫보정의 전처리 과정을 수행하였으며, 이 과정과 측광 과정은 이전의 연구와 같다 (Jeon et al. $2005 \mathrm{~b}, 2007)$. 이 영역에서 측광한 별은 모두 5,6000 여 개이며, 이들 모두에 대해 각각의 비교성을 설정하여 차등등급을 구한 후 광도곡선을 컴퓨터 화면에 하나씩 띄워서 육안으로 변광 여부를 확인하였다. 측광 과정 과 변광성을 찾는 과정은 Jeon (2008)과 같은 방법으로 이루어졌다.

\section{3. 결과}

표 1 은 관측된 변광성에 관련된 좌표자료와 구해진 물 리량을 모은 것이다. 표 1 에서 첫 번째와 두 번째 칸은
변광성 번호와 각 변광성에 대한 비교성 번호를 나타 낸 것이고, $2 \mathrm{MASS}$ 의 $\mathrm{ID}$ 는 $\mathrm{J} 2000.0$ 의 좌표를 대신하였 고, USNO-B1.0의 이름도 같이 수록하였다. 다섯 번째, 여섯 번째 칸의 평균 등급과 색지수는 각각의 변광성 에 대한 비교성의 표준등급에 차등등급의 전체 평균값 을 더하는 방식으로 구해졌다. 하지만 V1 V4 변광 성은 $V$ 등급이 너무 밝아서 표준화 과정에서 얻은 변 광성의 등급을 그대로 사용하였다. 이 과정에서 표준 성은 Joshi et al. (1983)의 M29성단에 대한 측광 자료 를 이용하였다. 이어서 관측으로부터 얻어진 Epoch, 주기, 변광진폭 및 변광성 분류를 나타내었고, 마지막 에 알려진 변광성의 이름을 수록하였다. 변광성 분류 는 GCVS의 분류법을 따랐다. $\mathrm{L}$ 은 느리게 변하는 불 규칙 변광성이며, 그 중에서 만기형은 $\mathrm{LB}$ 로 분류되고, $\mathrm{LPB}$ 는 하루 이상의 긴 주기를 가지는 $\mathrm{B}$ 형 변광성이 다. 구해진 주기는 측광의 정밀도 보다 좋은 $V$ 등급만 이 이용되었다.

모두 48 개의 변광성 중에서 3 개만이 기존에 알려 진 것이며, 45 개는 새로 찾아낸 변광성이다. 이들은 $\delta$ Scuti형 단주기 변광성 5 개, Cepheid형 변광성 1개, 식 쌍성 16 개(V14포함), $\beta \mathrm{Cep}$ 형 1 개, $\mathrm{LB}$ 형 3 개, $\mathrm{LPB}$ 형 2 개, L형 18 개 및 분류가 안되는 별이 2 개이다. 
표 1.- M29 영역에서 관측된 변광성의 물리량.

\begin{tabular}{|c|c|c|c|c|c|c|c|c|c|c|}
\hline \multicolumn{2}{|c|}{ Name } & \multicolumn{2}{|l|}{ ID } & \multirow[t]{2}{*}{$\overline{\langle<\rangle}$} & \multirow[t]{2}{*}{$\overline{\langle B\rangle-<V>}$} & \multirow[t]{2}{*}{$\mathrm{Epoch}^{a}$} & \multirow{2}{*}{$\begin{array}{c}\text { Period } \\
\text { (day) }\end{array}$} & \multirow{2}{*}{$\begin{array}{c}\text { Amp. } \\
V\end{array}$} & \multirow[t]{2}{*}{ Type } & \multirow[t]{2}{*}{ Remark } \\
\hline $\mathrm{V}$ & $\mathrm{C}$ & 2MASS & USNO-B1.0 & & & & & & & \\
\hline $\mathrm{V} 1^{b}$ & $\mathrm{C} 2$ & $20235100+3829343$ & 1284-0419751 & 8.549 & 0.490 & - & - & - & EA & V2031 Cyg \\
\hline $\mathrm{V} 2$ & $\mathrm{C} 25$ & $20211448+3820298$ & 1283-0439386 & 8.696 & 0.012 & - & - & - & - & \\
\hline $\mathrm{V} 3$ & $\mathrm{C} 14$ & $20223557+3807457$ & $1281-0483664$ & 8.408 & 1.097 & - & - & - & - & \\
\hline $\mathrm{V} 4^{b}$ & $\mathrm{C} 2$ & $20230286+3827210$ & 1284-0419096 & 9.308 & 0.584 & - & - & - & BCEP & \\
\hline V5 & $\mathrm{C} 4$ & $20213512+3836477$ & 1286-0407719 & 9.831 & 0.511 & 4617.215 & 0.14546 & 0.02 & DSCT & \\
\hline V6 & C30 & $20204709+3817066$ & $1282-0465720$ & 9.935 & 1.514 & 4621.880 & 2.51681 & 0.11 & LB & \\
\hline $\mathrm{V} 7$ & $\mathrm{C} 6$ & $20264517+3813435$ & $1282-0470802$ & 9.742 & 2.520 & - & - & - & $\mathrm{L}$ & \\
\hline $\mathrm{V} 8^{b}$ & $\mathrm{C} 10$ & $20222792+3846515$ & $1287-0408300$ & 10.353 & 0.494 & - & - & - & $\mathrm{L}$ & \\
\hline V9 & $\mathrm{C} 13$ & $20231221+3834298$ & $1285-0407754$ & 10.467 & 0.605 & - & - & - & $\mathrm{L}$ & \\
\hline V10 & $\mathrm{C} 14$ & $20224184+3810375$ & 1281-0483782 & 10.615 & 0.706 & 4618.269 & 1.59050 & 0.06 & EB? & \\
\hline V11 & $\mathrm{C} 1$ & $20220760+3823509$ & $1283-0440462$ & 10.718 & 0.461 & - & - & - & $\mathrm{L}$ & \\
\hline $\mathrm{V} 12$ & $\mathrm{C} 12$ & $20271021+3854016$ & 1289-0410899 & 10.665 & 1.006 & - & - & - & $\mathrm{L}$ & \\
\hline V13 & C30 & $20220297+3855018$ & $1289-0407745$ & 11.008 & 0.644 & - & - & - & EW? & \\
\hline V14 & $\mathrm{C} 18$ & $20233377+3853407$ & 1288-0411856 & 10.950 & 0.930 & - & - & - & EW or $\mathrm{L}$ & \\
\hline V15 & $\mathrm{C} 13$ & $20232605+3836144$ & 1286-0409249 & 11.062 & 0.635 & 4617.235 & 0.10417 & 0.01 & DSCT & \\
\hline V16 & $\mathrm{C} 28$ & $20263678+3826403$ & 1284-0421049 & 11.004 & 1.050 & - & - & - & L & \\
\hline V17 & $\mathrm{C} 20$ & $20215400+3850276$ & $1288-0410272$ & 11.394 & 0.583 & - & - & - & EA & \\
\hline V18 & C32 & $20255805+3821076$ & $1283-0443351$ & 11.545 & 3.719 & - & - & - & $\mathrm{L}$ & KY Cyg \\
\hline V19 & $\mathrm{C} 6$ & $20265572+3812524$ & 1282-0470949 & 11.455 & 0.937 & - & - & - & $\mathrm{L}$ & \\
\hline V20 & $\mathrm{C} 6$ & $20264457+3817202$ & $1282-0470780$ & 11.707 & 5.210 & - & - & - & $\mathrm{L}$ & V1387 Cyg \\
\hline V21 & $\mathrm{C} 21$ & $20212569+3839120$ & 1286-0407505 & 11.615 & 0.638 & - & - & - & EA & \\
\hline $\mathrm{V} 22$ & C31 & $20241223+3844533$ & 1287-0409707 & 11.707 & 0.452 & - & - & - & $\mathrm{L}$ & \\
\hline $\mathrm{V} 23$ & $\mathrm{C} 10$ & $20224015+3852378$ & $1288-0411142$ & 11.858 & 2.270 & - & - & - & $\mathrm{L}$ & \\
\hline $\mathrm{V} 24^{b}$ & $\mathrm{C} 7$ & $20250866+3829230$ & 1284-0420509 & 12.151 & 0.427 & - & - & - & LPB & \\
\hline $\mathrm{V} 25$ & C6 & $20265802+3813048$ & $1282-0470983$ & 12.238 & 0.491 & 4617.459 & 0.57803 & 0.02 & DSCT & \\
\hline V26 & C19 & $20255915+3826292$ & 1284-0420838 & 12.308 & 0.540 & - & - & - & L & \\
\hline V27 & C9 & $20254903+3847292$ & $1287-0410488$ & 12.354 & 0.584 & - & - & - & $\mathrm{L}$ & \\
\hline $\mathrm{V} 28^{b}$ & $\mathrm{C} 8$ & $20240226+3839380$ & 1286-0409569 & 12.327 & 1.239 & - & - & - & LB & \\
\hline V29 & $\mathrm{C} 28$ & $20270378+3829157$ & $1284-0421327$ & 12.868 & 0.779 & 4618.204 & 2.93147 & 0.15 & EA & \\
\hline V30 & $\mathrm{C} 17$ & $20212193+3833186$ & $1285-0406387$ & 12.859 & 1.073 & - & - & - & $\mathrm{L}$ & \\
\hline V31 & $\mathrm{C} 22$ & $20263285+3847298$ & 1287-0410944 & 13.007 & 0.737 & - & - & - & $\mathrm{L}$ & \\
\hline V32 & C5 & $20203539+3850351$ & $1288-0408832$ & 13.058 & 0.859 & - & - & - & $\mathrm{L}$ & \\
\hline V33 & $\mathrm{C} 13$ & $20230675+3832015$ & 1285-0407699 & 13.205 & 0.790 & 4621.416 & 3.97516 & 0.12 & LPB? & \\
\hline V34 & $\mathrm{C} 11$ & $20230719+3853533$ & $1288-0411523$ & 13.168 & 2.135 & - & - & - & $\mathrm{L}$ & \\
\hline V35 & C34 & $20211322+3845273$ & 1287-0407006 & 13.241 & 0.877 & 4617.176 & 0.06104 & 0.02 & DSCT & \\
\hline V36 & $\mathrm{C} 1$ & $20220827+3827214$ & 1284-0418032 & 13.284 & 0.937 & - & - & - & EA & \\
\hline V37 & $\mathrm{C} 27$ & $20211825+3812440$ & $1282-0466231$ & 14.140 & 2.371 & - & - & - & $\mathrm{L}$ & \\
\hline V38 & $\mathrm{C} 24$ & $20244750+3810584$ & $1281-0485723$ & 13.816 & 1.261 & 4619.196 & 1.91012 & 0.41 & EA & \\
\hline V39 & $\mathrm{C} 29$ & $20272437+3843063$ & $1287-0411465$ & 13.975 & 1.110 & 4617.508 & 0.61429 & 0.21 & EA & \\
\hline $\mathrm{V} 40$ & $\mathrm{C} 23$ & $20221996+3812386$ & $1282-0467153$ & 14.020 & 1.244 & 4617.152 & 4.75872 & 0.31 & EA & \\
\hline V41 & $\mathrm{C} 26$ & $20234116+3827000$ & 1284-0419627 & 14.075 & 2.149 & 4618.511 & 3.43873 & 0.55 & CEP & \\
\hline V42 & C33 & $20214655+3815517$ & $1282-0466694$ & 14.223 & 1.138 & 4617.309 & 0.06187 & 0.05 & DSCT & \\
\hline V43 & C31 & $20234755+3839011$ & 1286-0409452 & 14.474 & 0.962 & 4618.207 & 0.30651 & 0.53 & EW & \\
\hline V44 & $\mathrm{C} 15$ & $20243844+3848093$ & $1288-0412406$ & 15.124 & 1.099 & 4717.688 & 0.39811 & 0.4 & EW & \\
\hline V45 & $\mathrm{C} 16$ & $20203089+3844502$ & $1287-0406350$ & 15.163 & 1.177 & 4617.386 & 0.75498 & 0.5 & EW & \\
\hline V46 & $\mathrm{C} 2$ & $20240518+3829433$ & 1284-0419921 & 15.233 & 1.148 & - & - & - & LB & \\
\hline V47 & $\mathrm{C} 1$ & $20222187+3825469$ & $1284-0418348$ & 15.845 & 1.015 & 4617.462 & 0.34987 & 0.39 & EW & \\
\hline V48 & C35 & $20252575+3826522$ & - & 16.364 & 1.411 & 4617.671 & 0.53670 & 1.05 & $\mathrm{EA}$ & \\
\hline
\end{tabular}

$a$ : HJD 2450000.0+

${ }^{b}$ : Joshi et al. (1983)에 의해 $50 \%$ 이상의 확율로 성단 구성원으로 분류된 별. 
표 2.- GCVS 에 올라있는 관측 영역 내의 알려진 변광성.

\begin{tabular}{|c|c|c|c|c|c|}
\hline \multicolumn{4}{|c|}{ GCVS } & \multicolumn{2}{|c|}{ This paper } \\
\hline Name & Type & $<V>$ & Amp. & ID & variability \\
\hline $\mathrm{V}^{2031 \mathrm{Cyg}^{c}}$ & $\mathrm{EA}$ & 8.53 & 0.14 & 7 & EA \\
\hline NSV 25111 & & 8.70 & 0.06 & 8 & \\
\hline NSV $25141^{c}$ & & 8.88 & 0.09 & 24 & \\
\hline NSV $25143^{c}$ & E: & 8.85 & 0.08 & 25 & \\
\hline $\mathrm{NSV} 13067^{c}$ & & 8.86 & 0.13 & 27 & VAR: \\
\hline V1322 $\mathrm{Cyg}^{c}$ & GCAS & 8.77 & 0.93 & 32 & VAR: \\
\hline NSV $25136^{c}$ & & 9.23 & 0.31 & 33 & \\
\hline V1388 Cyg & LB & 11.30 & 0.90 & 43 & \\
\hline NSV $25123^{c}$ & VAR: & 10.00 & 2.80 & 61 & none \\
\hline NSV $25139^{c}$ & & 10.14 & 0.31 & 75 & none \\
\hline NSV $25148^{c}$ & VAR: & 10.55 & 0.17 & 88 & none \\
\hline NSV 25138 & & 10.49 & 0.41 & 90 & none \\
\hline KY Cyg & $\mathrm{LC}$ & 13.50 & 2.00 & 192 & $\mathrm{~L}$ \\
\hline V1387 Cyg & LB & 13.00 & 3.30 & 203 & $\mathrm{~L}$ \\
\hline NSV $25144^{c}$ & VAR: & 12.38 & 0.71 & 256 & none \\
\hline NSV 25128 & VAR: & 12.00 & 2.95 & 285 & none \\
\hline NSV 25135 & VAR: & 12.83 & 0.07 & 545 & none \\
\hline NSV 25137 & VAR: & 13.50 & - & 866 & \\
\hline V1380 Cyg & UV: & 15.30 & 0.70 & 2530 & VAR: \\
\hline V1655 Cyg & $\mathrm{M}$ & 12.00 & 2.80 & - & \\
\hline V1657 Cyg & $\mathrm{M}$ & 13.00 & 2.10 & - & \\
\hline V1320 Cyg & EA/DS: & 15.90 & 2.60 & - & \\
\hline V1382 Cyg & LB: & 17.50 & 0.70 & - & \\
\hline V0498 Cyg & EA/DM & 9.98 & 0.77 & - & \\
\hline V1323 Cyg & IS: & 15.10 & 0.90 & - & \\
\hline V1384 Cyg & $\mathrm{L}$ & 16.80 & 1.30 & - & \\
\hline
\end{tabular}

새로 발견된 45 개의 변광성 외에 관측된 영역에는 표 1 에서 알려진 3 개의 변광성을 포함하여 GCVS에 모 두 26 개의 변광성이 수록되어 있다. 이들을 표 2 에 수 록하였다. 표 2 에서 앞쪽 4 번째 칸까지는 GCVS 자료 를 정리하였고, 마지막 두 칸에 이 연구 과정에서 얻 은 별번호와 변광여부를 나타내었다. 표 1 에서 변광성 으로 분류된 알려진 세 변광성, $\mathrm{V} 2031 \mathrm{Cyg}(\mathrm{V} 1), \mathrm{KY}$ $\mathrm{Cyg}(\mathrm{V} 18), \mathrm{NSV} 25144$ (V20)외에 세 개는 변광성의 가 능성이 높으나 확실하게 변광성이 아닌 것으로 분류 된 7 개를 포함하여 13 개는 변광성일 가능성이 거의 없 고, 알려진 변광성의 좌표에서 별을 찾을 수 없는 경 우(ID가 없는 아래쪽 별)도 7 개가 있었다 (그림 8 참 조).

표 1 과 표 2 의 별들을 모두 그림 2 의 색-등급도 $(\mathrm{CMD})$ 에 나타내었다.

$B$ 와 $V$ 등급은 관측된 기기등급을 $\mathrm{M} 29$ 에 대한 Joshi et al. (1983)의 광전측광 등급을 이용하여 표준화하 였으며, 영연령주계열 (ZAMS)와 $\delta$ Scuti 불안정대는 $E(B-V)=0.65$, 거리지수 10.17 (Wang \& Hu 2000)를 적용하였다.

그림 2 의 별들에 대한 표준편차 값을 그림 3 에 보였
다.

10 등급보다 밝은 별은 포화되어 등급오차가 크게 나타나는 경우가 많다. 변광진폭이 작거나, 식을 일으 키는 부분이 적은 변광성의 경우 전체적인 측광의 표 준편차는 크지 않아서 일일이 육안으로 변광 여부를 판 단할 수 밖에 없었다.

표 1 과 표 2 의 목록에서 성단 구성원으로 분류된 별 은 모두 15 개 이다.

\section{1. 주기가 결정된 변광성}

그림 4 와 그림 5 는 각각 주기가 결정된 식변광성과 맥 동변광성의 위상맞추기 결과이다. 관측과정에서 $B$ 필 터와 와 $V$ 필터에 대해 같은 노출시간을 적용하여 $B$ 등 급의 측광 오차가 $V$ 등급 보다 더 크며, $B$ 등급 광도곡 선의 분산이 크게 나타났다.

그림 4 의 $\mathrm{V} 43, \mathrm{~V} 44, \mathrm{~V} 45$ 와 $\mathrm{V} 47$ 은 $V$ 와 $B$ 등급에 대 해 비슷한 진폭을 보이고 있어서 $\mathrm{W} \mathrm{UMa형} \mathrm{변광성으}$ 로 분류하였다. 주기가 긴 식변광성은 $\mathrm{V} 10$ 을 제외하면 5 개가 $\mathrm{EA}$ 형이며, $\mathrm{V} 10$ 은 작은 진폭과 긴 주기를 가지 지만 진폭비 $(\Delta B / \Delta V)$ 가 거의 1 에 가까워 맥동변광 성으로 볼 수는 없고, 주극소와 부극소가 있는 $\mathrm{EB}$ 형 식 쌍성으로 보인다. 이들 식쌍성은 Joshi et al. (1983)의 성단 구성원에 속한 별은 하나도 없으며, 그림 1 에서 성단의 중심으로부터 멀리 떨어져 있는 등 성단 구성 원의 가능성은 거의 없다.

그림 5 의 맥동변광성 8 개는 모두 새로 발견한 것이 다. 그 중에서 5 개( $\mathrm{V} 5, \mathrm{~V} 15, \mathrm{~V} 25, \mathrm{~V} 35$ 및 $\mathrm{V} 42)$ 는 $\delta$ Scuti형 변광성, 1개(V41)는 Cepheid형 변광성이다. 나 머지 V6와 V33은 장주기형 변광성으로서 변광진폭이 $V$ 등급에서 불과 0.11 등급과 0.12 등급에 불과하다. 이 장주기형 2 개는 그림 1 에서 보면 성단의 중심에서 많이 벗어나 있고, 그림 2 의 $\mathrm{CMD}$ 상의 위치로 볼 때 $\mathrm{M} 29$ 성 단의 구성원으로 보기는 어렵다. V41의 Cepheid형 변 광성은 성단의 중심에 비교적 가깝게 위치하지만 성단 의 맥동 불안정대를 훨씬 벗어나 있어서 성단의 구성 원으로 볼 수는 없겠다.

그림 6은 이산 푸리에 변환(Discrete Fourier Transform)과 다중회귀에 의한 주기 분석(Kim \& Lee $1995)$ 을 수행하여 얻은 파워 스펙트럼이다 비록 관측 일 간의 영점변화에 따른 낮은 주파수가 나타나서 정 확한 주기 분석이 어렵지만 각 $\delta \mathrm{Scuti}$ 변광성의 주된 주파수가 잘 나타난다. 그림 7 은 5 개의 $\delta$ Scuti형 변광 성에 대한 광도곡선이다. 그림 7 의 실선은 그림 5 의 결 과에서 얻은 주기분석의 결과를 실선으로 중첩하여 나 타낸 것이다.

주기 분석의 결과는 표 3 에 정리하였다. 표 3 의 주 파수는 Breger et al. (1993)에 의해 제안된 신호대 잡 


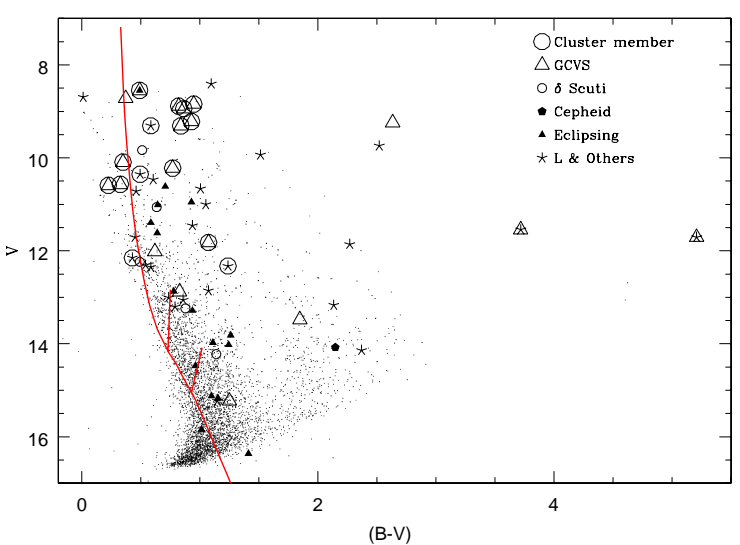

그림 2.- 관측된 영역의 색-등급도. 작은원은 $\delta$ Scuti 형 변광성, 검은오각형은 Cepheid 변광성, 검은삼각형은 식 쌍성, 별모양은 긴주기로 변광하거나 분류가 어려운 별 들을 각각 나타낸 것이다. 그리고 큰원은 Joshi et al. (1983)에 의해 성단 별로 분류된 것이며, 큰 삼각형은 $\mathrm{GCVS}$ 목록에서 변광성으로 분류된 것이다. 영연령주 계열(ZAMS)과 $\delta$ Scuti 불안정대는 각각 Sung \& Bessell (1999)와 Breger (1979)의 경험적 결과이다.

음비 $(S / N) \geq 4.0$ 인 것을 택하였다. 각 $\delta$ Scuti 별의 변광진폭이 작아서 소형망원경으로 정밀한 결과를 얻 기가 어려워서 $\mathrm{V} 25$ 를 제외한 나머지 4 개의 별에서 하 나의 주기만 찾아졌다. 5 개 중에서 V 35 만이 그림 2 에 서 M29의 맥동불안정대에 놓여 있다. 하지만 그림 1 에 서 V35는 성단의 중심에서 많이 벗어나 있어서 성단내 별로 보기는 어렵고, 결과적으로 성단내 $\delta \mathrm{Scuti}$ 변광 성은 하나도 없는 것으로 보인다.

$\mathrm{M} 29$ 는 아주 젊은 산개성단이어서 밝은 $\mathrm{O}$ 형, $\mathrm{B}$ 형의 별이 많이 포함되어 있고, $\delta$ Scuti 변광성의 불안정대가 $V=13$ 보다 어두운 영역에 놓여 있다. 따라서 성단 내 $\delta$ Scuti 형 변광성은 기대하기 어렵고, $\beta$ Cephei 또는 $\mathrm{LPB}$ 형 별이 기대되는데 이번 연구에서는 주기가 결정 된 8 개의 맥동변광성 중에 성단 구성원이 하나도 없었 다.

\section{2. 주기 결정이 안된 변광성.}

표 1 에서 주기결정이 안된 변광성에 대한 광도곡선을 그림 8에 보였다. $\mathrm{V} 1, \mathrm{~V} 18, \mathrm{~V} 20$ 을 제외한 모두가 새로 찾은 변광성인데 주기가 길거나 비주기성이어서 주기 결정이 어려운 별들이다. 어두운 별은 $B$ 등급의 높은 분산을 고려하여 $V$ 등급 자료만을 나타내었으나 밝은 별은 $V$ 등급이 포화되어 $B$ 등급의 괄도곡선을 나타내 었다. 그림 8의 V1은 Boeche et al. (2002)에 따르면 주 기가 2.70465 일 로 알려졌다. 우리의 결과에는 $V$ 등급 이 포화되어 광도곡선을 얻을 수 없었고, 단지 $B$ 등급에 서만 광도곡선을 얻어서 식을 확인할 수 있었다. V18,

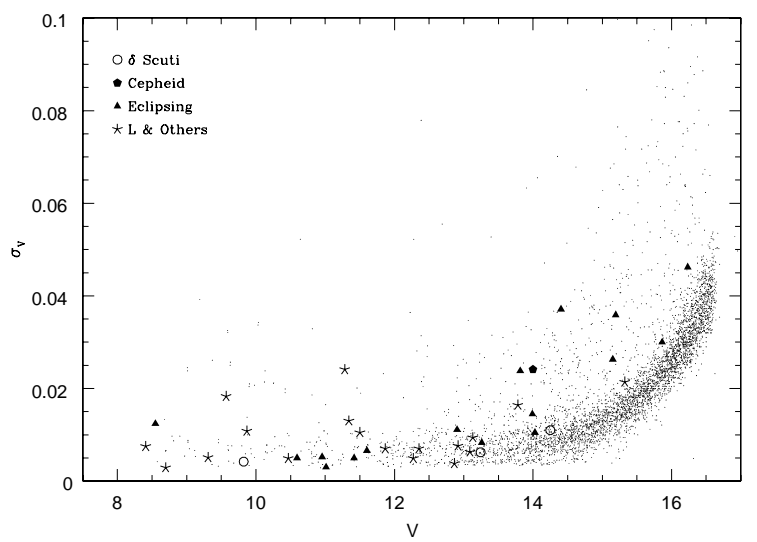

그림 3.- 측광 결과 얻어진 별의 표준화 등급과 표준편 차. 변광성 기호는 그림 2 와 같다.

$\mathrm{V} 20$ 은 $\mathrm{GCVS}$ 목록에 올라 있으며, 각각 $\mathrm{LC}, \mathrm{LB}$ 형으 로 분류되었다.

표1의 10 번째 칸에 변광형태가 기록되어 있다. 모두 31 개의 별 중에서 식쌍성으로 분류된 것 중 $\mathrm{V} 1, \mathrm{~V} 14$, $\mathrm{V} 17, \mathrm{~V} 21, \mathrm{~V} 36$ 은 뚜렷이 EA형으로 나타나고, V13은 $\mathrm{EW}$ 형으로 추정된다. 느리게 변하는 불규칙 변광성 $\mathrm{L}$ 형으로 분류된 것은 $\mathrm{V} 7, \mathrm{~V} 8, \mathrm{~V} 9, \mathrm{~V} 11, \mathrm{~V} 12, \mathrm{~V} 16, \mathrm{~V} 18$, $\mathrm{V} 20, \mathrm{~V} 22, \mathrm{~V} 23, \mathrm{~V} 26, \mathrm{~V} 27, \mathrm{~V} 30, \mathrm{~V} 31, \mathrm{~V} 32, \mathrm{~V} 34, \mathrm{~V} 37$ 등 17 개이다. 이들 중 미세하게 변하는 경우는 변광 특성 을 완전하게 결정하기 위해서 더 정밀한 추가 관측이 이 루어져야 할 필요성이 크다. $\mathrm{V} 4$ 는 $\mathrm{BCEP}$ 형, $\mathrm{V} 28, \mathrm{~V} 46$ 은 $\mathrm{LB}$ 형, $\mathrm{V} 24, \mathrm{~V} 33$ 은 $\mathrm{LPB}$ 형으로 각각 분류되었다. 나 머지 2 개 $(\mathrm{V} 2, \mathrm{~V} 3)$ 는 변광만 확인되었다. 주기 결정이 안된 변광성 중에서 Joshi etal.(1983)에 의해 성단 구 성원으로 알려진 것이 5 개 $(\mathrm{V} 1, \mathrm{~V} 4, \mathrm{~V} 8, \mathrm{~V} 24, \mathrm{~V} 28)$ 가 포 함되어 있는데, $\mathrm{V} 24$ 는 그림 2 에서 M29의 SPB형 영역 에 위치하고, $\mathrm{V} 4$ 는 $\beta \mathrm{Cep}$ 영역에 위치하고 있다. V8도 $\beta \mathrm{Cep}$ 영역에 위치하고 있는데 광도곡선의 변화만으 로 확인하기는 어렵다.

\subsection{GCVS에 수록된 변광성.}

관측된 영역 내의 알려진 변광성은 $\mathrm{GCVS}$ 에서 모두 26 개를 찾아서 표2에 수록되었다. 이들 26 개 별 중에 서 위치 확인이 안된 7 개를 제외한 19 개 별의 광도곡선 을 그림 9 에 모두 나타내었다.

표 2 의 $\mathrm{GCVS}$ 에 수록된 26 개의 변광성 목록 중에서 3 개 (V2031 Cyg, KY Cyg, V1387 Cyg)는 우리 연구에 서도 표1에 각각 $\mathrm{V} 1, \mathrm{~V} 18, \mathrm{~V} 20$ 으로 올라 있다. 이들 외에 3 개의 변광가능 별이 분류되었는데 NSV 13067 과 $\mathrm{V} 1322 \mathrm{Cyg}$ 는 $V$ 등급은 너무 밝아서 포화된 관계로 사 용할 수 없고, 단지 $B$ 등급 자료로 나타내었는데 작은 진폭에 대해 광도곡선의 분산이 크게 나타난다. 또한 광도곡선의 분산이 너무 커서 변광 가능을 판단하기 어 


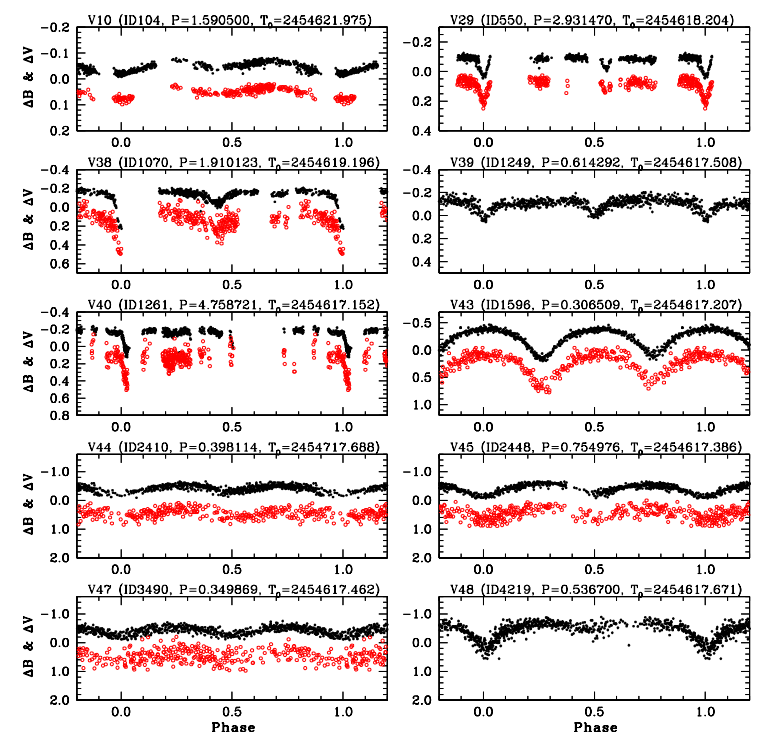

그림 4.- 주기가 결정된 식변광성의 위상맞추기 결과. 각각의 패널에서 위쪽은 $V$ 필터, 아래쪽은 $B$ 필터의 차등 등급이며, 평균값을 0 으로 정규화하여 $B$ 와 $V$ 의 측광 등 급 간의 구분을 위해 각각 일정 비율(등급축 값의 0.12 배) 로 값을 더하고 $(B)$ 빼주었다 $(V)$.

려운 별 6 개를 포함하여 변광 가능성이 없는 것으로 판 단된 7 개의 별에 대한 광도곡선도 그림 9 에 나타내었 다.

\section{4. 요약 및 검토}

보현산천문대의 단주기변광성 탐사연구(SPVS)의 일 환으로 젊은 산개성단 M29 영역에서 48개의 변광 성을 찾았는데 그 중에서 3 개는 알려진 변광성이며, 45 개는 새로운 변광성이었다. 이들은 $\delta$ Scuti형 5 개, Cepheid형 1 개, 식쌍성 16 개, $\beta$ Cep형 1 개, $\mathrm{LB}$ 형 3 개, $\mathrm{LPB}$ 형 2 개, $\mathrm{L}$ 형 18 개 및 분류가 안되는 별이 2 개였다.

이 성단의 체계적인 변광성 연구는 $\mathrm{Kim} \& \mathrm{Lee}$ (1996)가 유일한데 중심부 $8.1^{\prime} \times 8.1^{\prime}$ 영역에서 새로운 변광성 4 개를 포함하여 모두 8개의 변광성에 대한 광 도곡선이 주어져 있다. 이 중에서 Kim \& Lee (1996)의 KL96-ID\#8(NSV 25139)과 KL96-ID\#13은 이 연구에 서는 밝기 변화를 볼 수 없어서 변광성이 아니었는데, 비교성 선택의 문제가 있는 것으로 판단된다. KL96$\mathrm{ID} \# 2$ (NSV 25143), KL96-ID\#5(NSV 25136)는 변광여 부가 불확실하였으며, KL96-ID\#6(V1322 Cyg)은 단지 변광성 후보로 분류되었다. 그리고 나머지 3 개의 변 광성은 KL96-ID\#1(V2031 Cyg), KL96-ID\#64, KL96$\mathrm{ID} \# 104$ 는 이 연구에서 각각 $\mathrm{V} 1, \mathrm{~V} 41, \mathrm{~V} 46$ 이다. 특히 KL96-ID\#1은 2.70465 의 주기를 가진다 (Boeche et al. 2002).
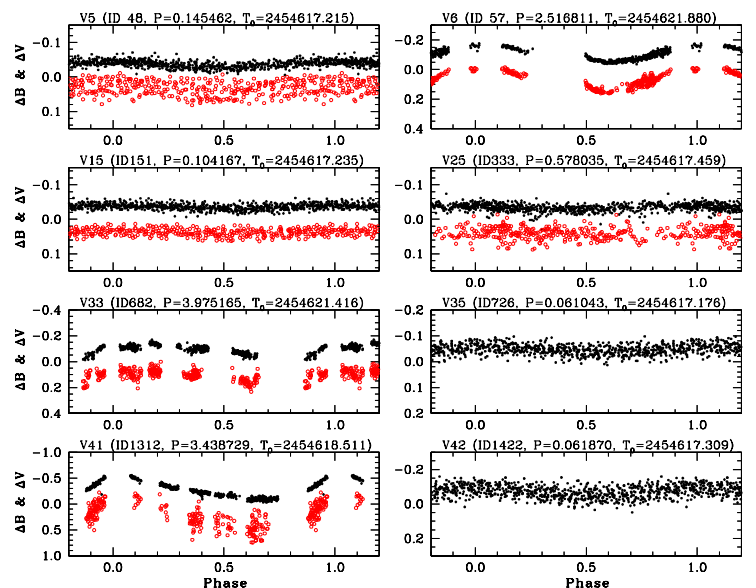

그림 5.주기가 결정된 맥동변광성의 위상맞추기 결과. 각 패널의 설명은 그림 2 와 같다. $\mathrm{V} 5, \mathrm{~V} 15, \mathrm{~V} 25, \mathrm{~V} 35$, $\mathrm{V} 42$ 는 $\delta \mathrm{Scuti}$ 형 변광성, $\mathrm{V} 41$ 은 Cepheid 변광성, V6은 $\mathrm{LB}$ 형, $\mathrm{V} 33$ 은 $\mathrm{LPB}$ 형으로 분류하였다.

표 3. $-\delta$ Scuti형 변광성의 주기분석 결과.

\begin{tabular}{ccccc}
\hline \hline Name & & Frequency $^{a, b}$ & Amp. $^{b, c}$ & $\mathrm{~S} / \mathrm{N}$ \\
\hline V5 & $f_{1}$ & 6.8769 & 0.02 & 13.6 \\
V15 & $f_{1}$ & 9.6000 & 0.02 & 8.7 \\
V25 & $f_{1}$ & 3.8259 & 0.01 & 4.1 \\
& $f_{2}$ & 17.2340 & 0.01 & 3.9 \\
V35 & $f_{1}$ & 16.3821 & 0.02 & 8.5 \\
V42 & $f_{1}$ & 16.1629 & 0.04 & 11.4 \\
\hline$a:$ In cycles per day. \\
${ }_{b}:$ V Const $+\Sigma_{j} A_{j} \cos \left\{2 \pi f_{j}\left(t-t_{0}\right)+\phi_{j}\right\}$, \\
$\quad t_{0}=$ HJD 2,450,000.0. \\
${ }^{c}:$ Total amplitude
\end{tabular}

특히 GCVS에 수록된 26 개의 별 중에서 약 6 개만이 변광 가능한 것으로 나타났다. 반면에 SPVS 시스템으 로 같은 영역에서 새로운 변광성을 45 개나 추가로 발 견하였다. SPVS 시스템이 비록 작은 구경의 망원경을 이용하지만 한 대상에 대해 많은 관측을 수행할 수 있 어서 긴주기로 미세하게 변하는 변광성을 찾는데 효율 이 아주 좋음을 알 수 있다.

\section{참고문헌}

Boeche, C., Munari, U., Tomasella, L., \& Barbon, R., 2002, Spectroscopic orbit of the eclipsing binary V2031 Cyg in the field of the open cluster NGC 6913=M 29, Inf. Bull. Variable Stars, 5237, 1

Boeche, C., Munari, U., Tomasella, L., \& Barbon, R., 2002, Kinematics and binaries in young stellar aggregates II. NGC 6913=M 29, A\&Ap, 415, 145 Breger, M., 1979, Delta Scuti \& Related Stars, PASP, 

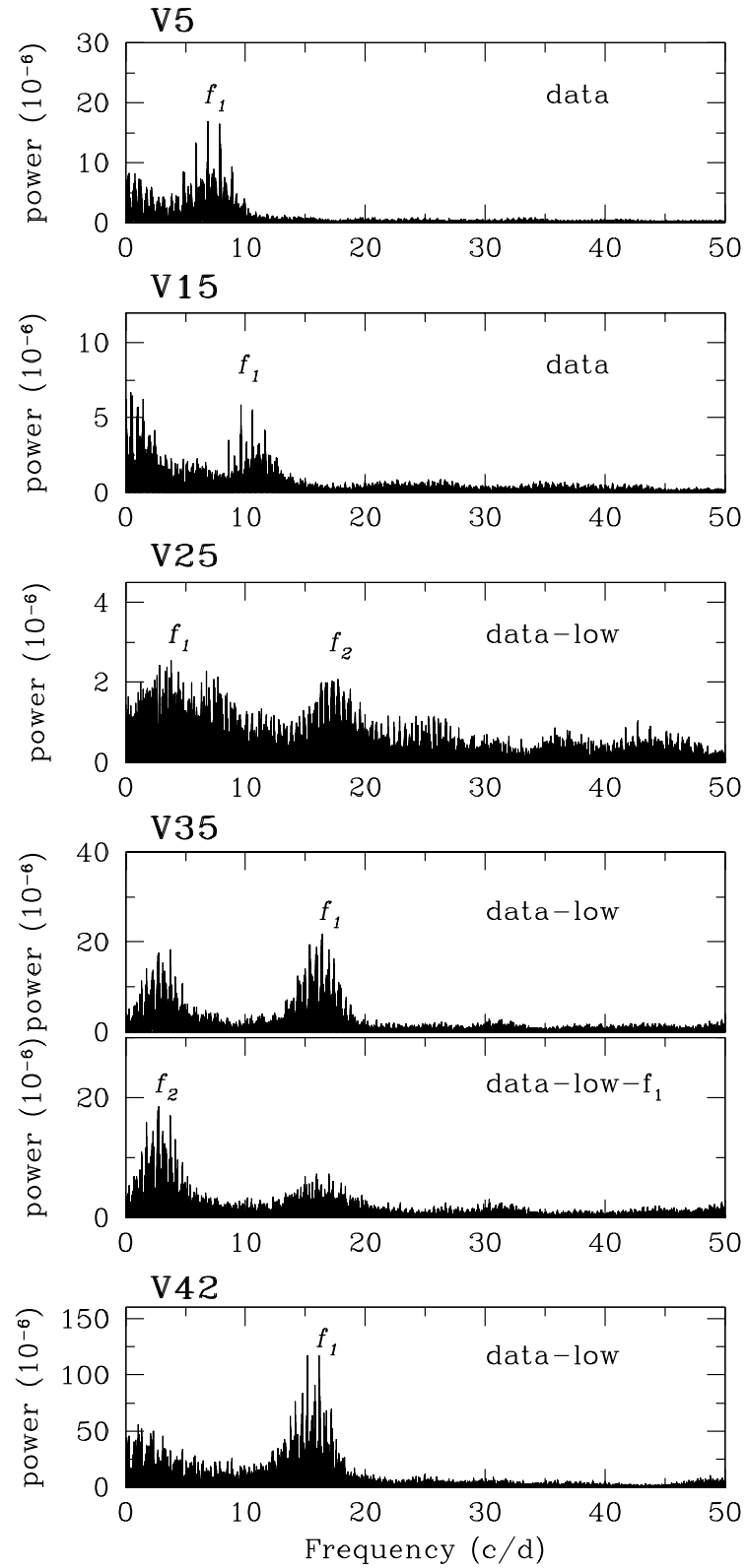

그림 6. $-\delta \mathrm{Scuti}$ 형 변광성의 Fourier 분석 결과로 얻은 파워 스펙트럼.
91,5

Breger, M., Stich, J., Garrido, R., et. al., 1993, Nonradial Pulsation of the Delta-Scuti Star Bu-Cancri in the Praesepe Cluster, A\&Ap., 271, 482

Jeon, Y.-B., 2008, Variable Stars in the region of an open cluster M50, PKAS, 23, 17

Jeon, Y.-B., Nam, K.-H., Park, Y.-H., et al. 2007, Preliminary Results for Short-Period Variability Survey (SPVS): New Field Variable Stars, PKAS, 22,141

Jeon, Y.-B., Kim, S.-L., Park, Y.-H., et al., 2005a, Short-Period Variability Survey (SPVS) in BOAO, PKAS, 20, 21

Jeon, Y.-B., Park, Y.-H., Nam, K.-H., et al., 2005b, New Variable Stars around the Cepheid Variable TU Cas, PKAS, 20, 29

Joshi, U. C. \& Sanwal, B. B., 1983, Photometry of the open cluster NGC 6913, PASJ, 35, 405

Kim, S.-L. \& Lee, S.-W., 1995, CCD Photometry of a Delta Scuti Star in an Open Cluster II. BT CNC in the Praesepe, JKAS, 28, 197

Kim, S.-L. \& Lee, S.-W., 1996, Variable stars in the open cluster M29, JKAS, 29, 31

Massey, P. \& Davis, L. E., 1992, A User's Guide to Stellar CCD photometry with IRAF

Samus, N. N., Durlevich, O. V., et al., 2004, Combined General Catalogue of Variable Stars (Samus+2004), VizieR Online Data Catalog, 2250

Stetson, P. B., 1987, DAOPHOT - A computer program for crowded-field stellar photometry, PASP, 99, 191

Sung, H. \& Bessell, M. S., 1999, UBVI CCD photometry of M35 (NGC 2168), MNRAS, 306, 361-370.

Wang, J.-J. \& Hu, J.-Y., 2000, Spectral classification and reddening in the young open cluster NGC 6913, A\&Ap, 356, 118 
V5 (ID48)

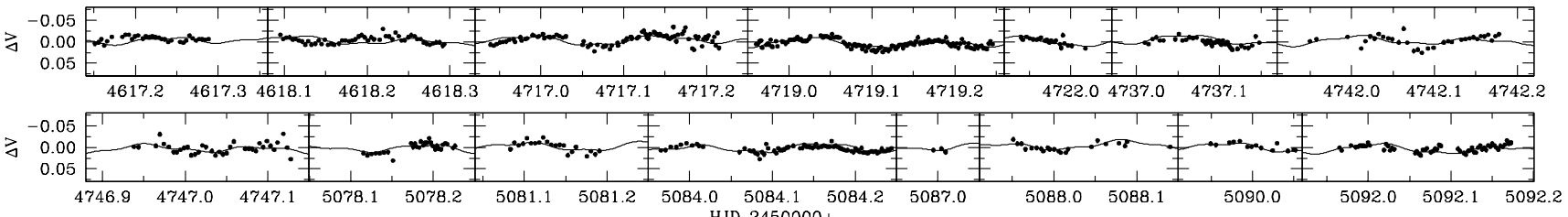

V15（ID151)
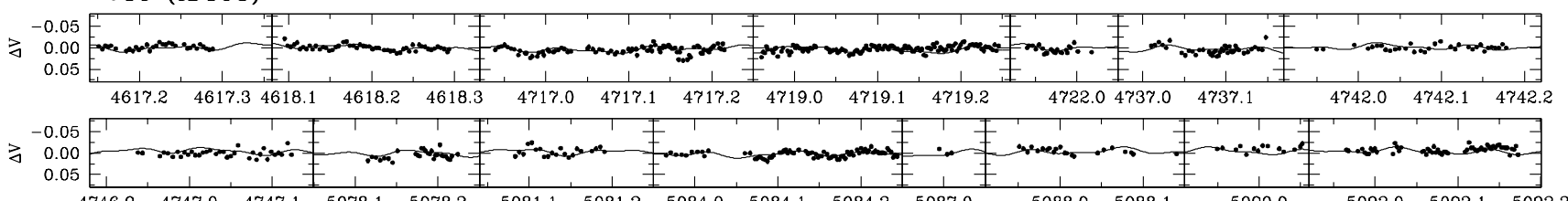

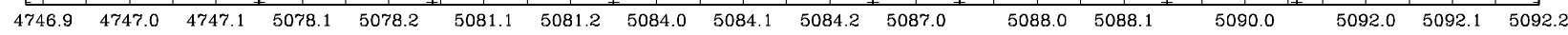
V25 (ID333)

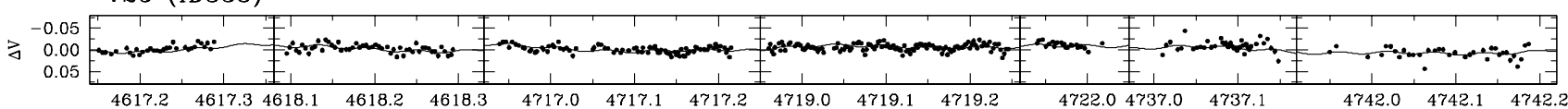

\begin{tabular}{rl|l}
$r$ \\
0.00
\end{tabular} V35 (ID726)

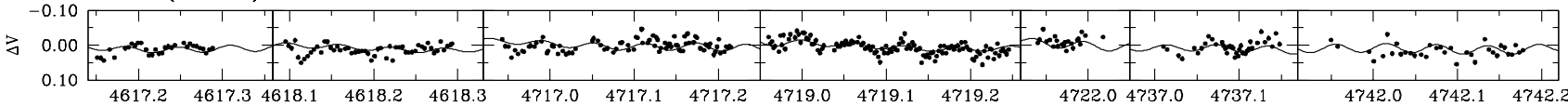

$\Rightarrow \begin{aligned} & { }_{0}^{0} 00 \\ & 0.10\end{aligned}$

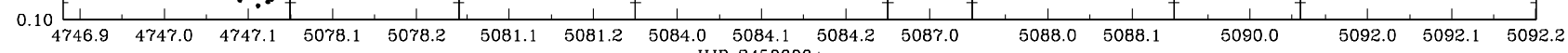
V42 (ID 1422)

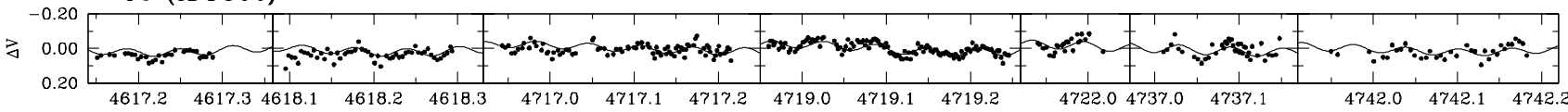

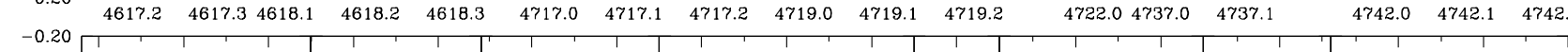

$\Rightarrow$\begin{tabular}{l}
0.00 \\
\hline
\end{tabular}

그림 7. $-\delta$ Scuti형 변광성의 광도곡선. 검은 점은 $V$ 필터의 관측자료이며, 실선은 주기분석의 결과를 중첩한 것이다. 각 패 널의 차등등급은 평균값을 0 으로 정규화한 것이다. 


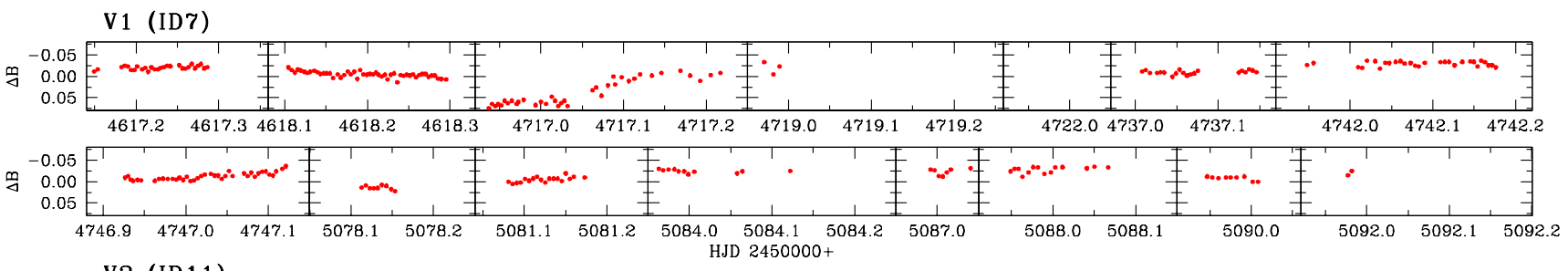

V2 (ID11)

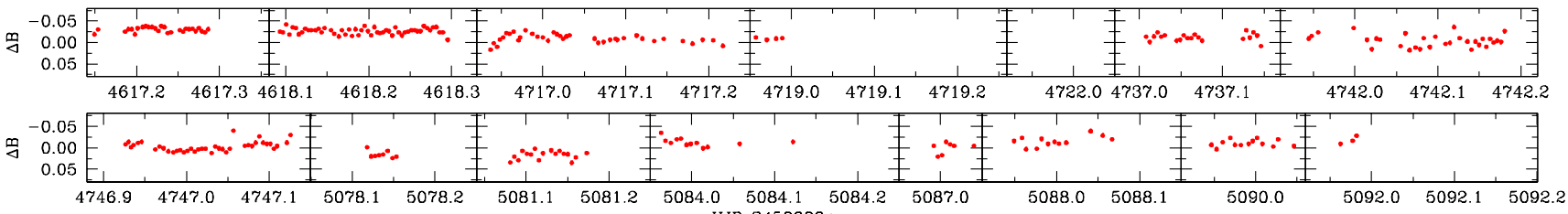

V3 (ID12)

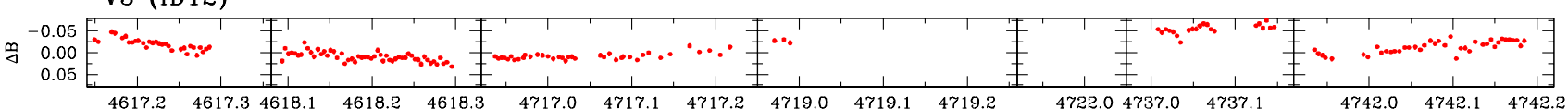

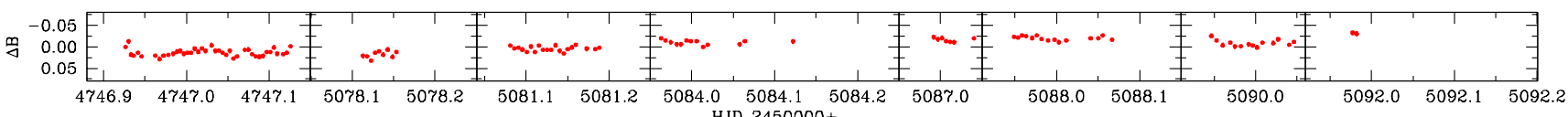
V4 (ID31)
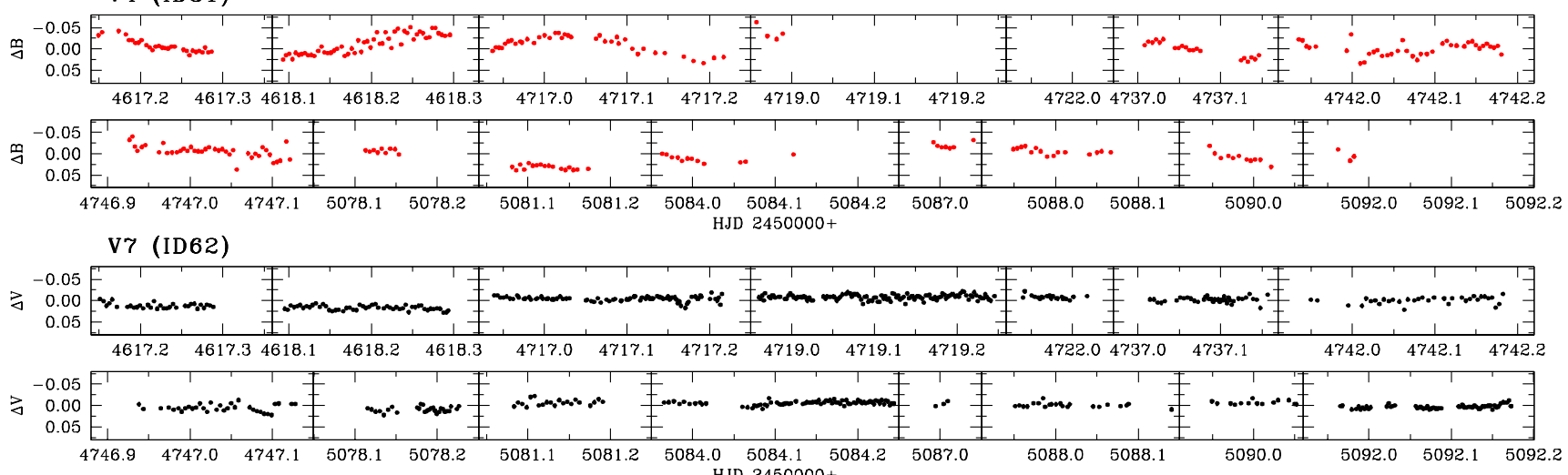
V8 (ID79)

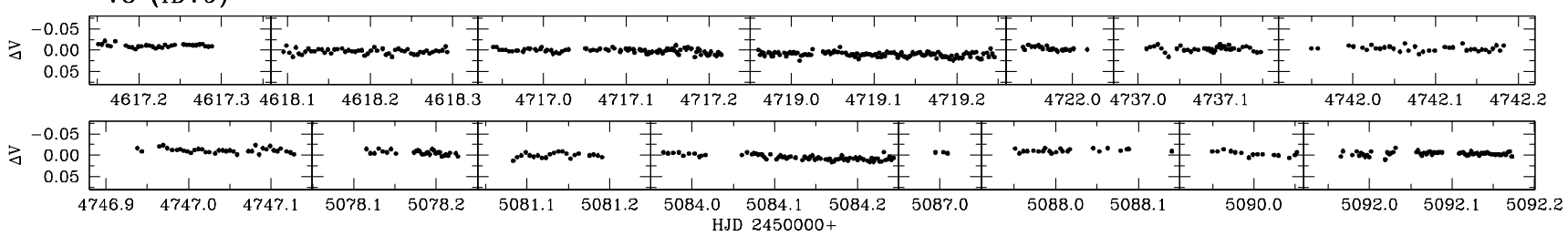

그림 8.- 변광성 분류 및 주기 결정이 안되는 변광성. 밝은 별( $\mathrm{V} 4$ 까지)에 대해서는 $V$ 등급이 포화되어 $B$ 등급을 적용 하였다. 각 패널의 차등등급은 평균값을 0 으로 정규화한 것이다. 
v9 (ID93)

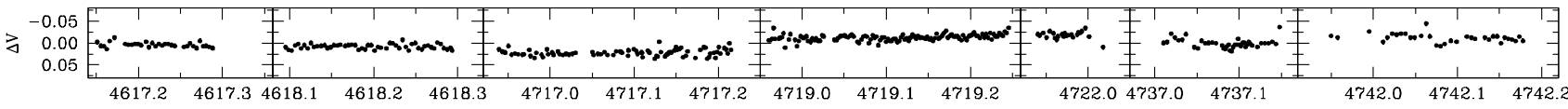

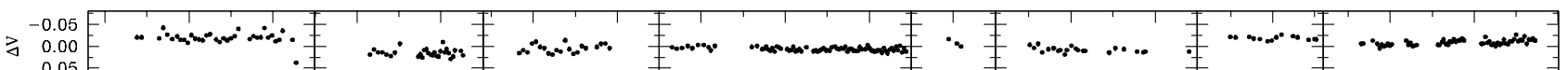

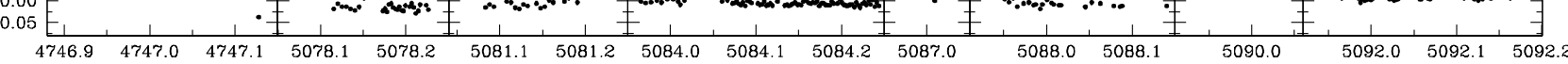
V11 (ID 106)

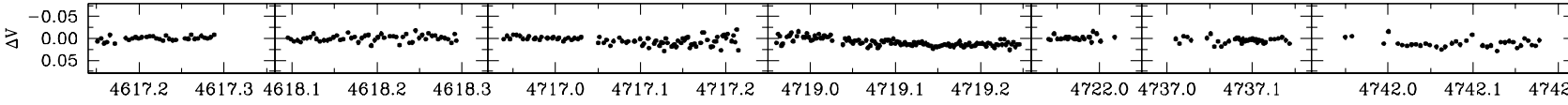

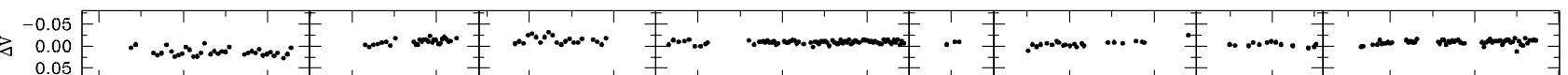

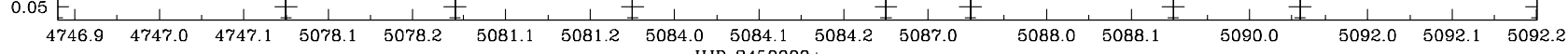
V12 (ID 110$)$

$8 \begin{aligned} 0.05 \\ 0.00\end{aligned}$

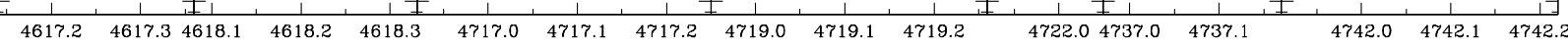

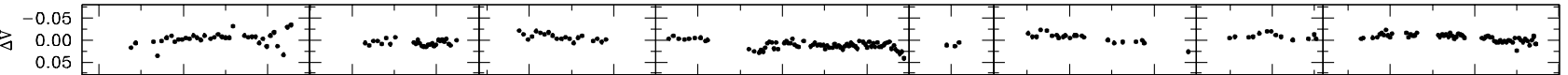

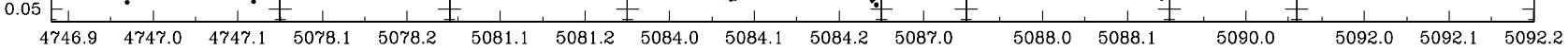
V13 (ID 146)

$r$
0.00

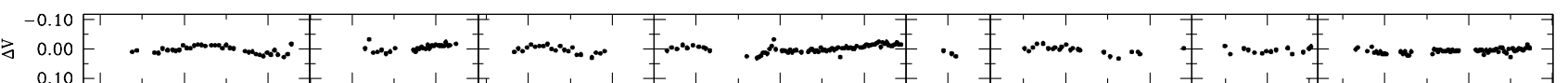

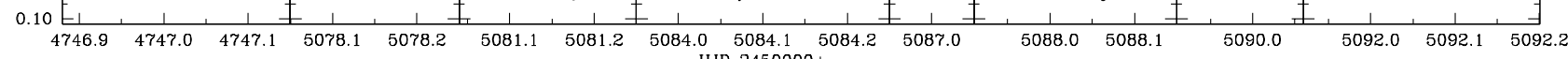
V14 (ID 148)

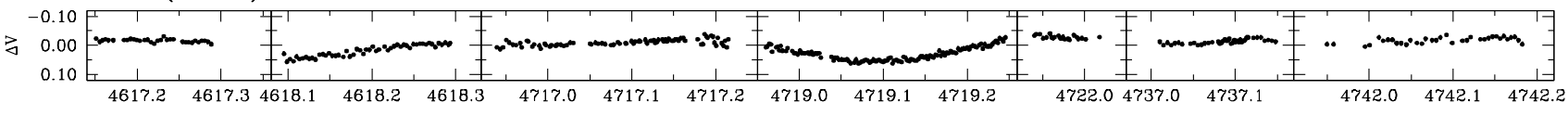

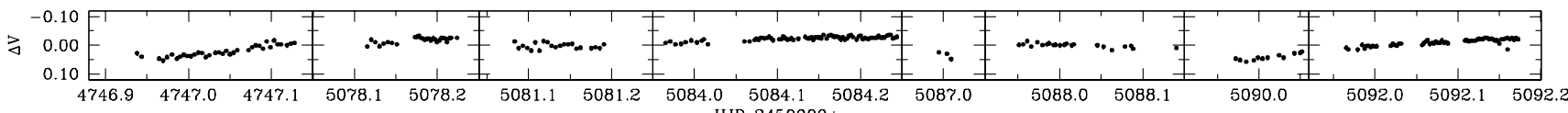
V16 (ID 158)

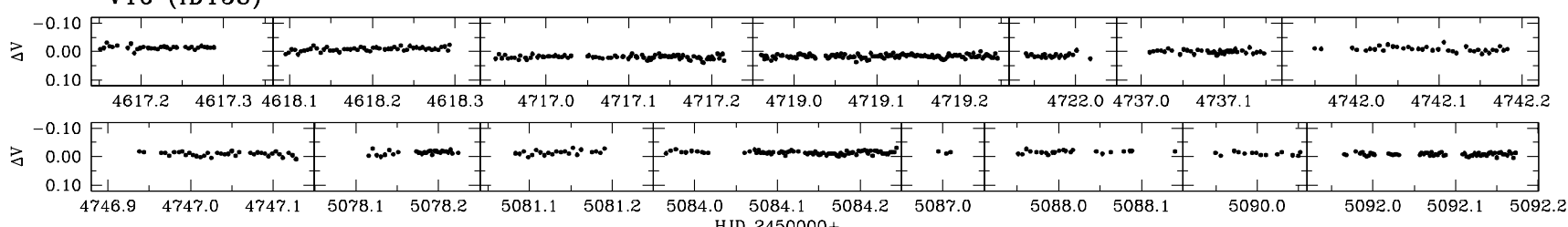

그림 8.- (계속). 


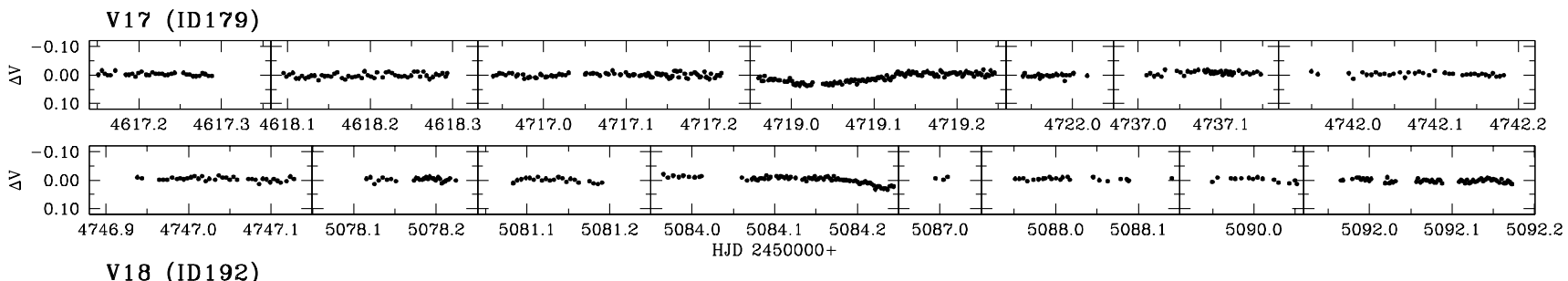

V18 (ID 192)

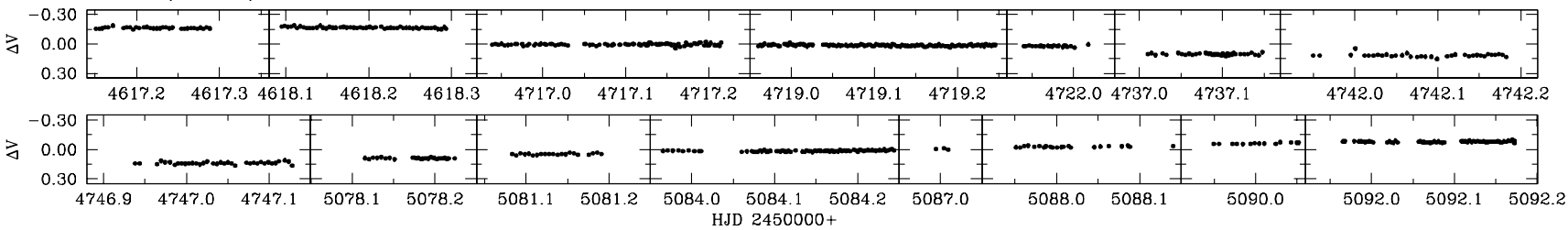
V19 (ID201)
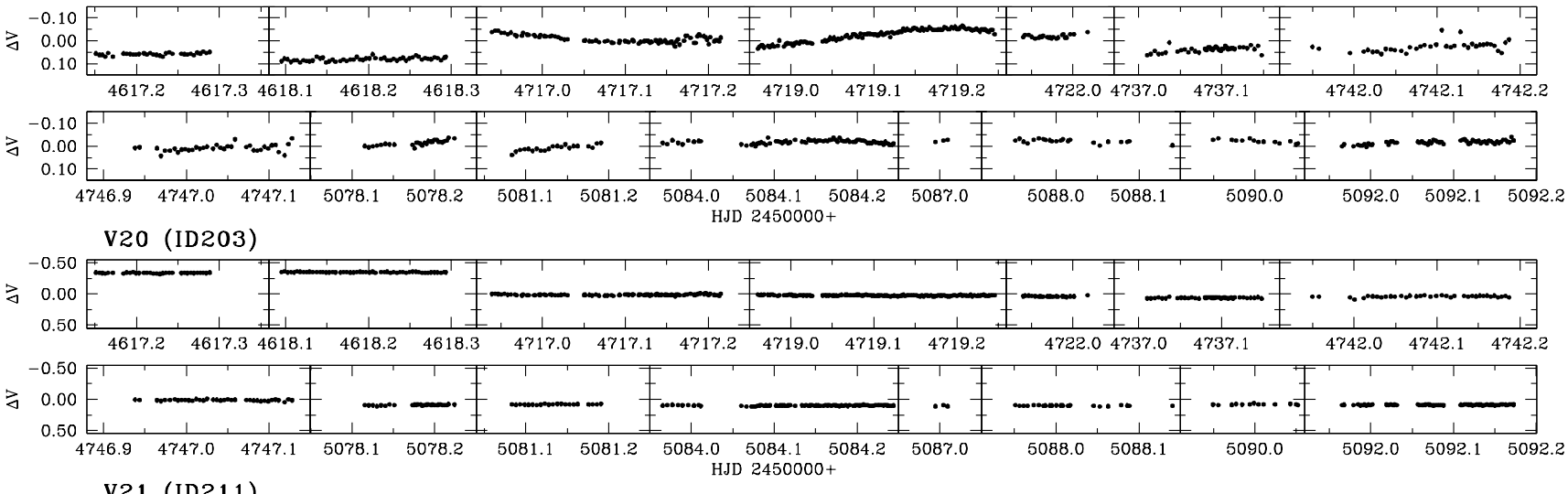
V21 (ID211)

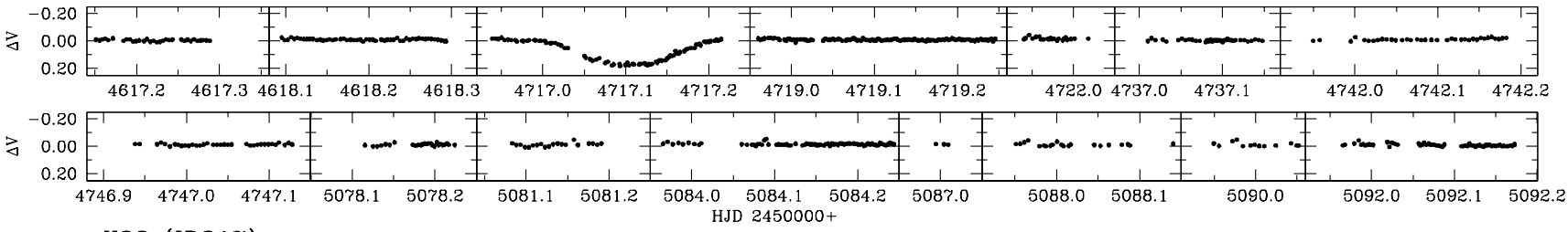
V22 (ID217)

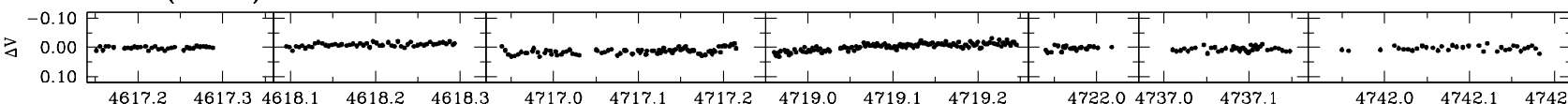

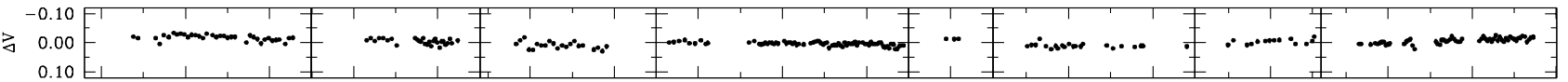

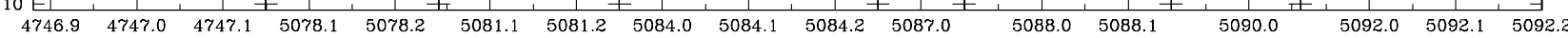
HJD $2450000+$

그림 8.- (계속). 


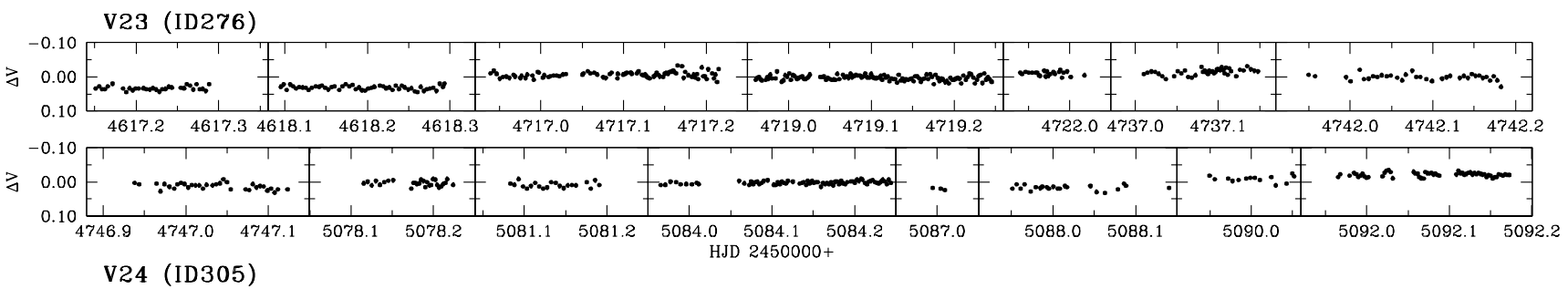

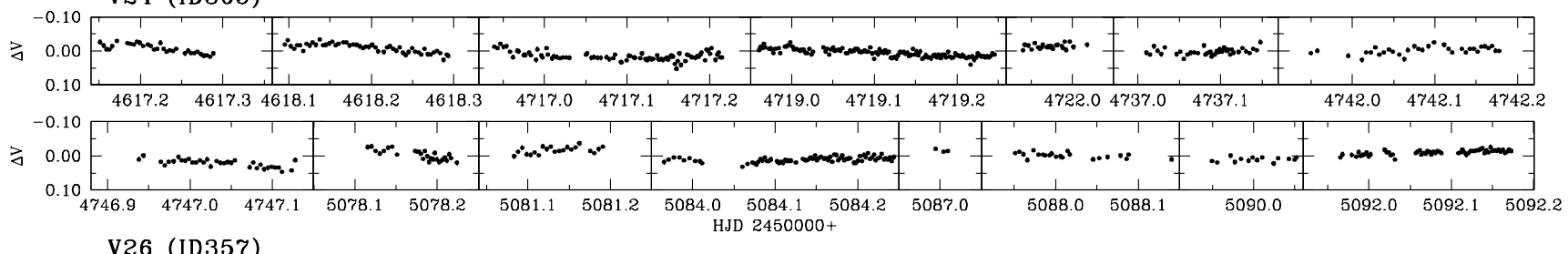
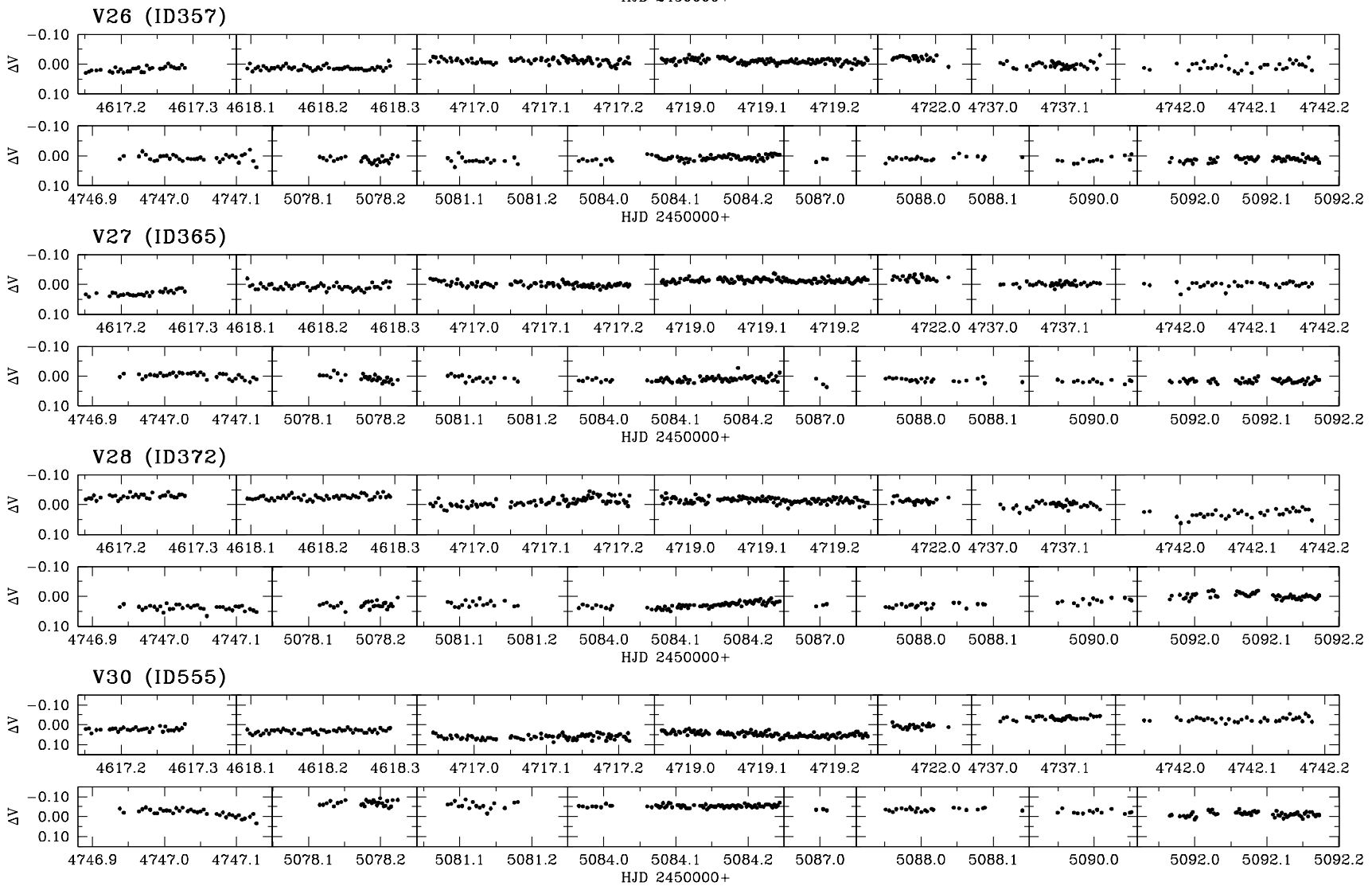

그림 8.- (계속). 


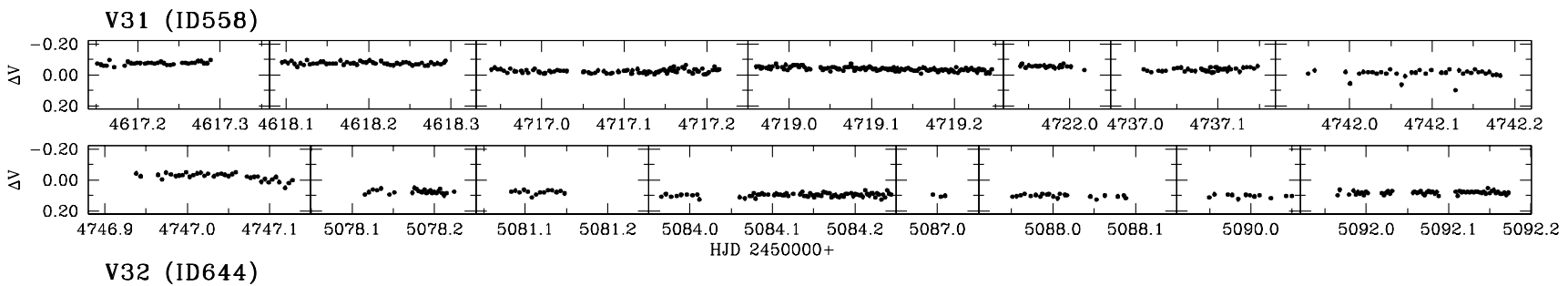

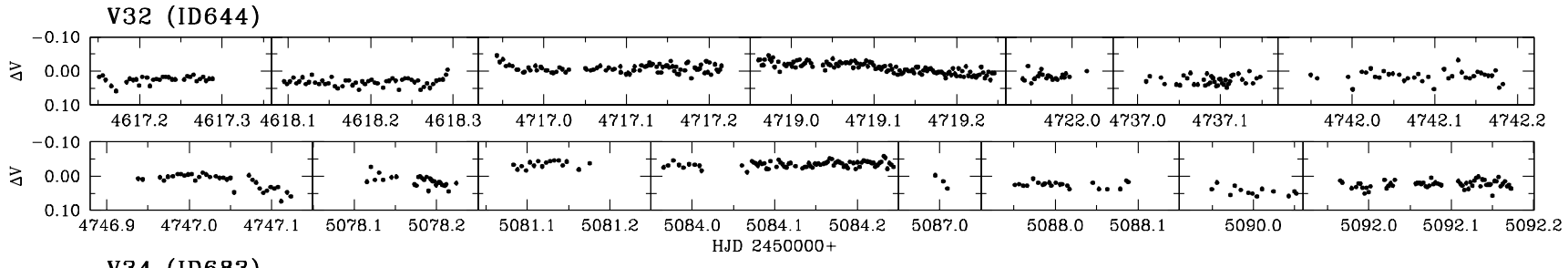
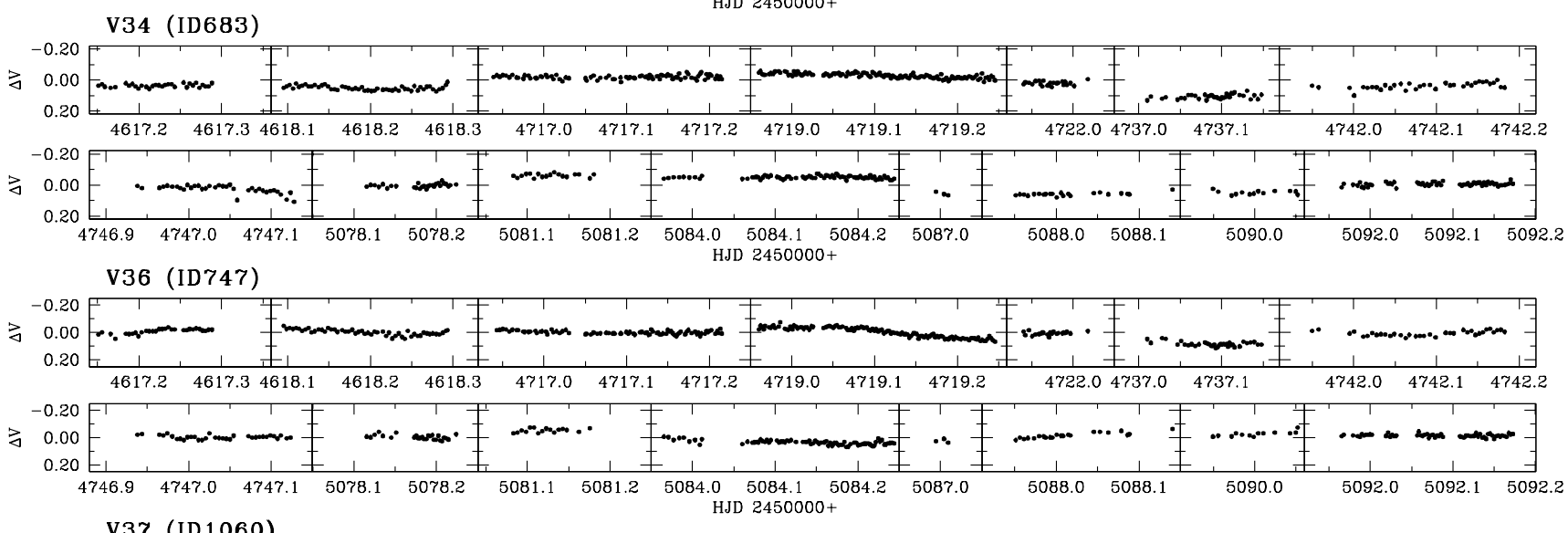
V37 (ID 1060)
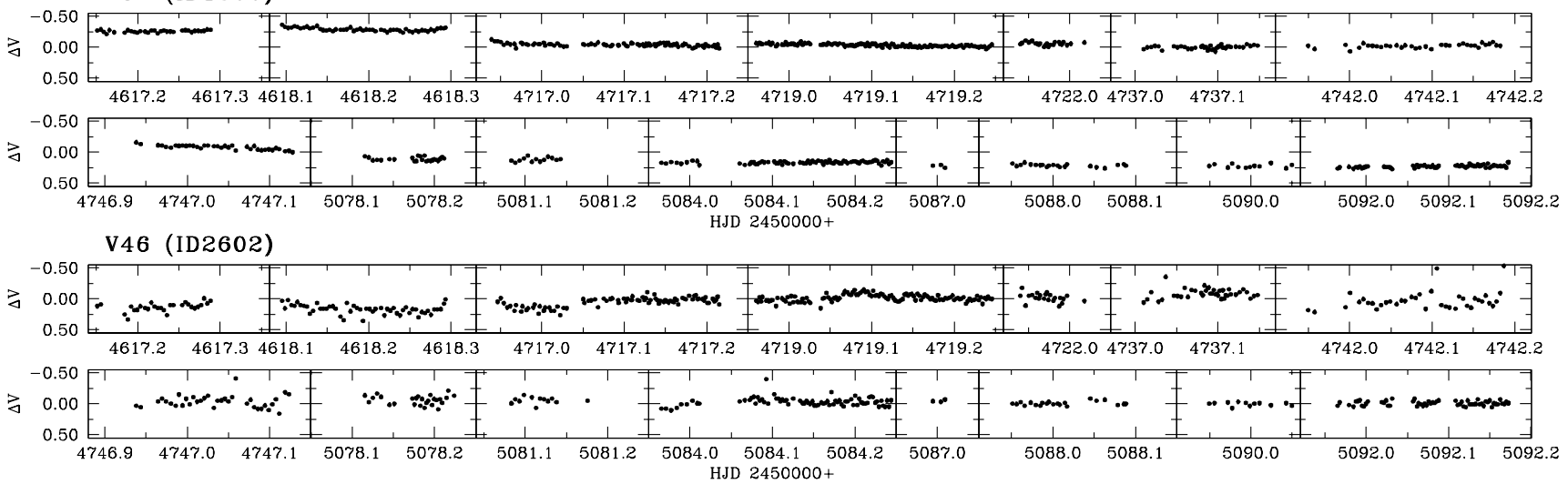

그림 8.- (계속). 
ID7 (V2031 Cyg)

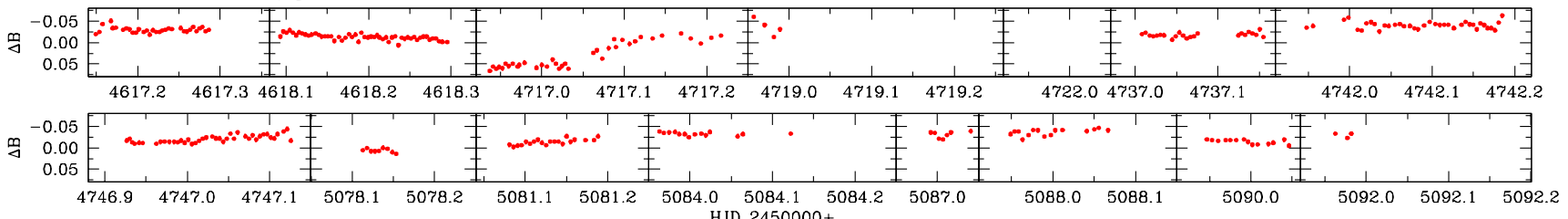

ID8 (NSV 25111)

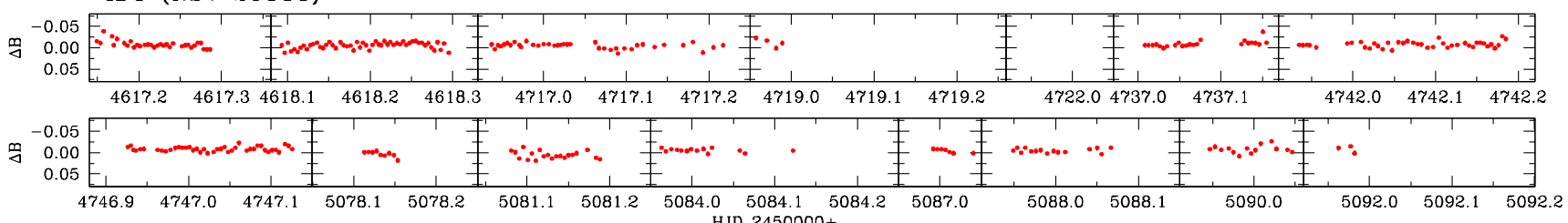

ID24 (NSV 25141)

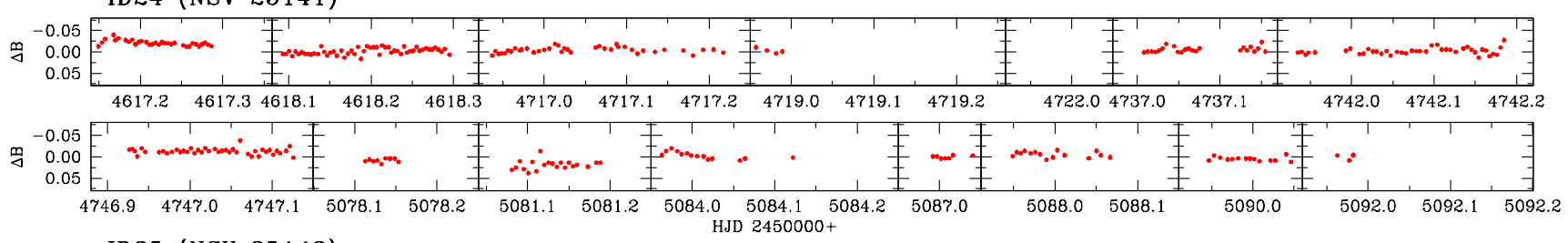

ID25 (NSV 25143)

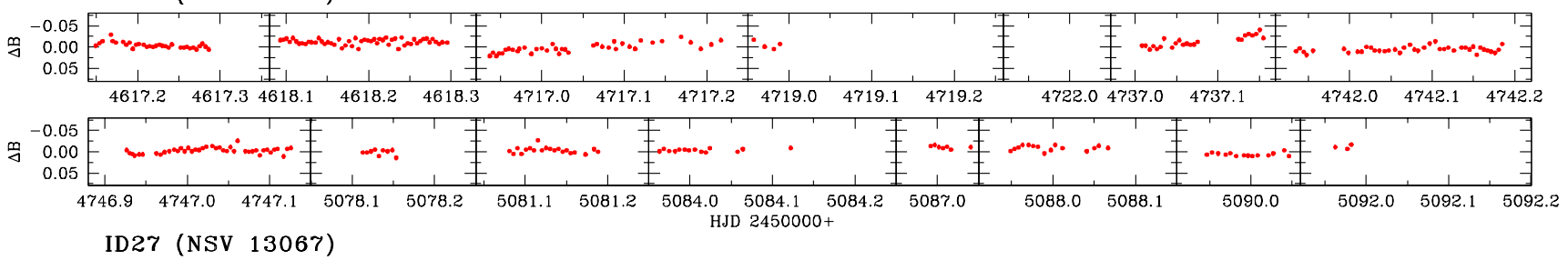

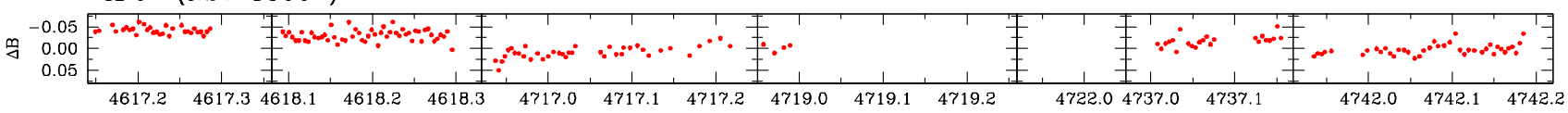

$m$
0.00
0.05 ID32 (V1322 Cyg)

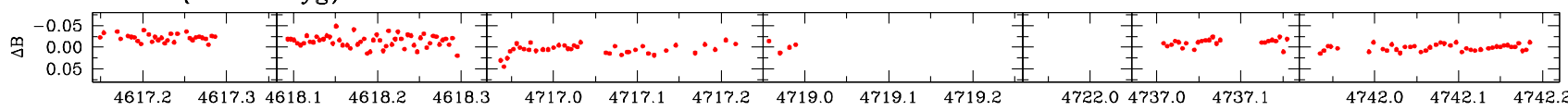

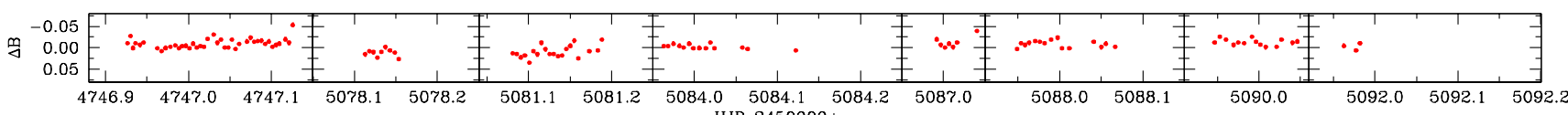

그림 9.- $\mathrm{GCVS}$ 에서 변광성으로 분류된 별들. 밝은 별(ID43까지)에 대해서는 $V$ 등급이 포화되어 $B$ 등급을 적용하였 다. 자세한 내용은 본문에 설명되었다. 
ID33 (NSV 25136)

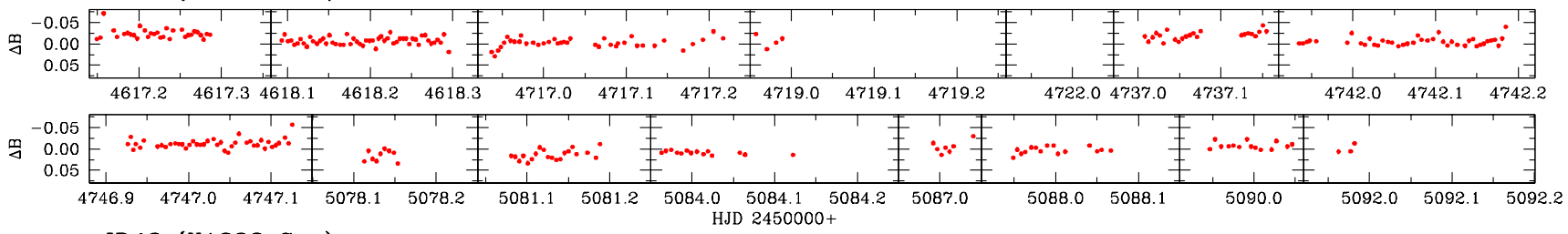
ID43 (V1388 Cyg)
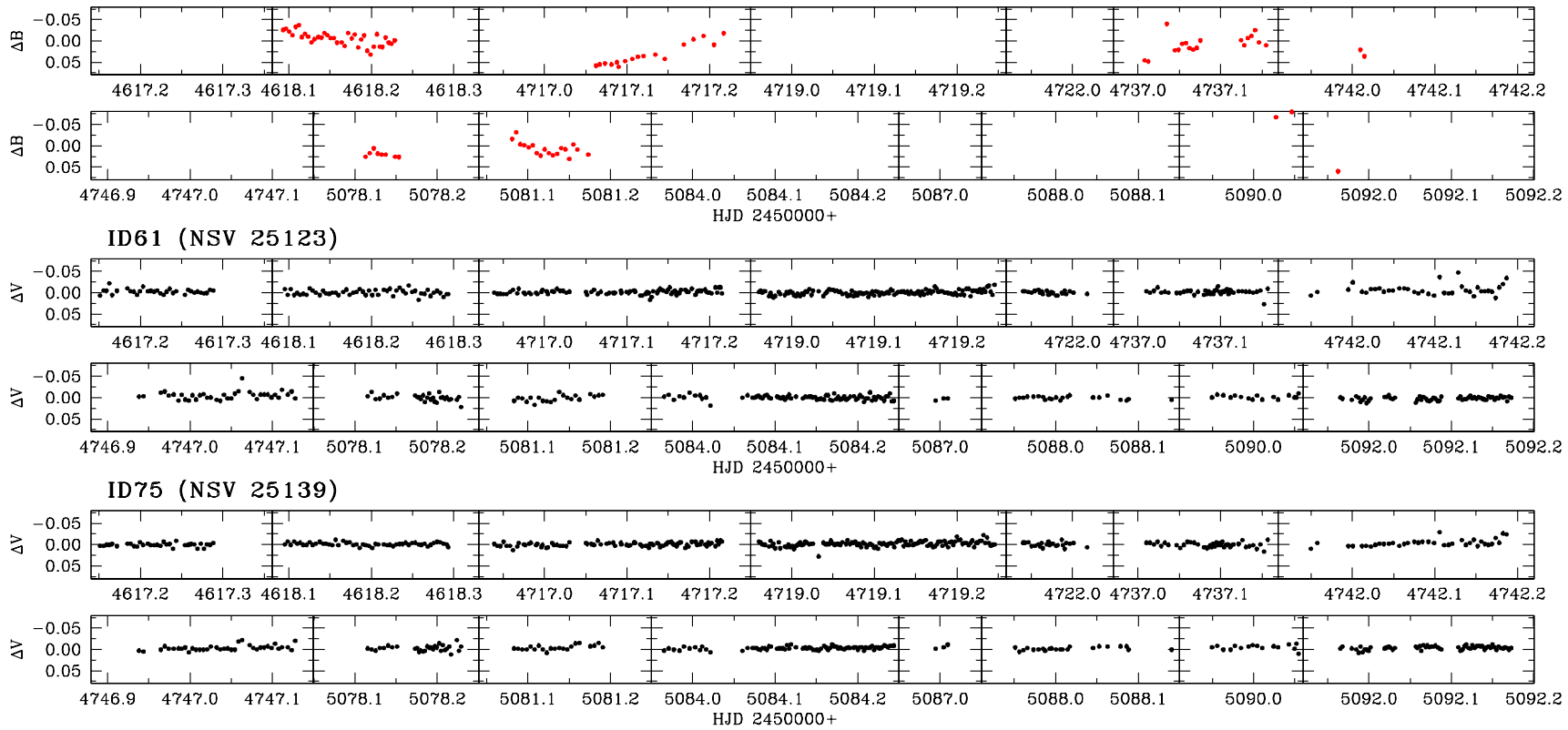
ID88 (NSV 25148)

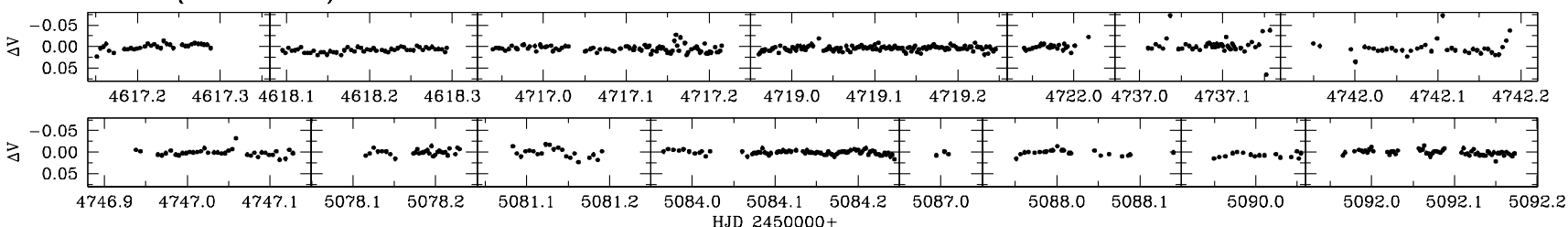
ID 90 (NSV 25138)

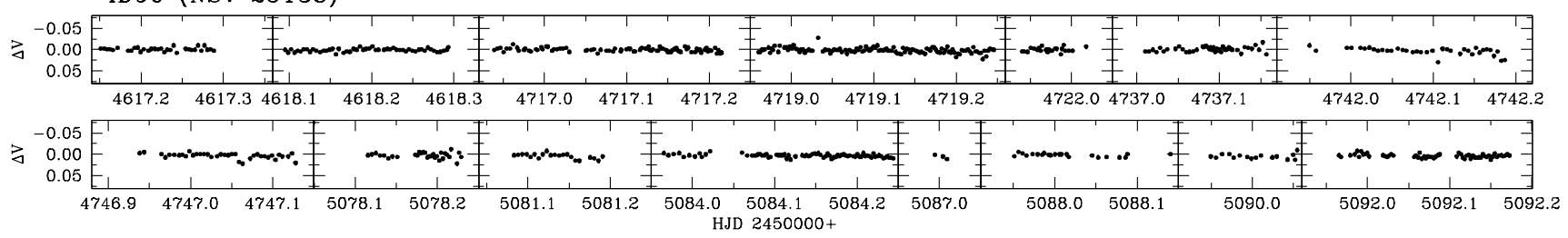

그림 9.-(계속). 
ID 192 (KY Cyg)
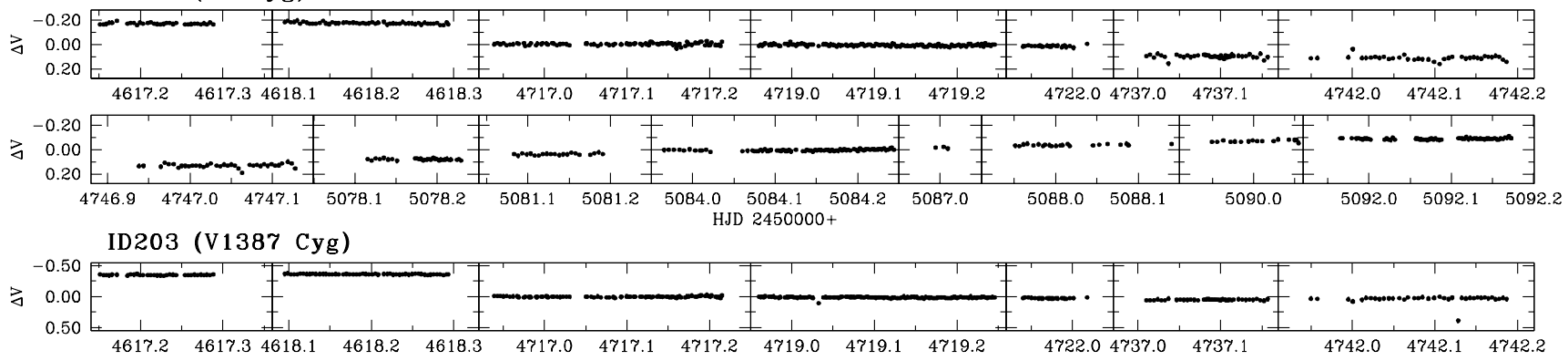

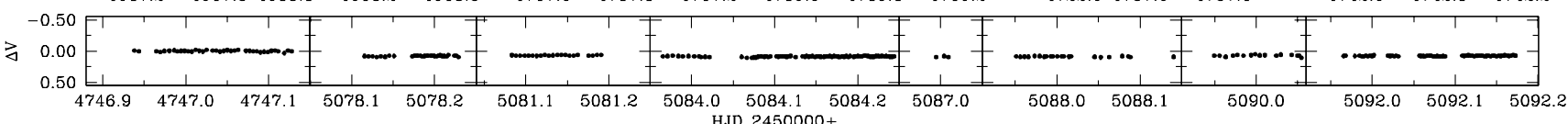
ID256 (NSV 25144)

8
0.00

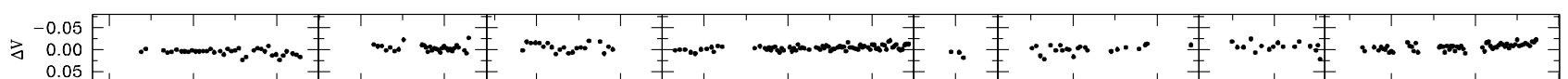

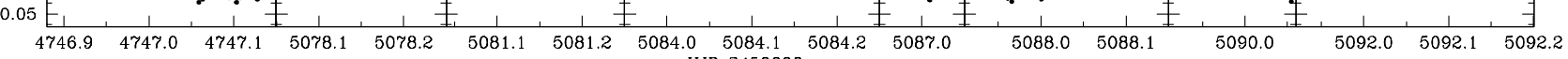
ID285 (NSV 25128)

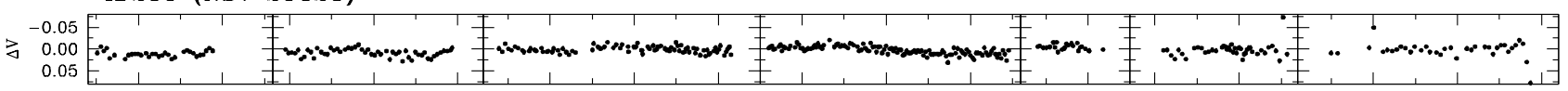

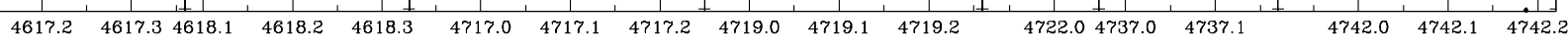
$\gtrsim \begin{array}{r}0.05 \\ 0.05\end{array}$

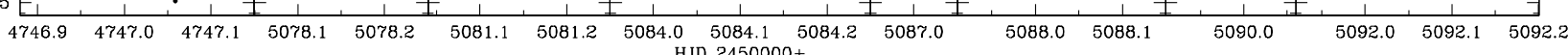
ID545 (NSV 25135)

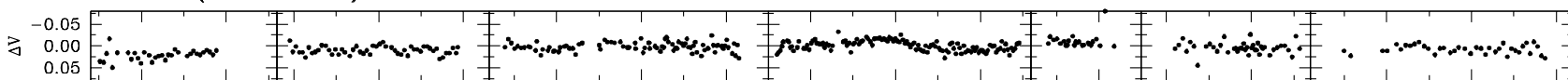

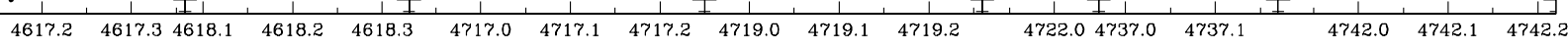

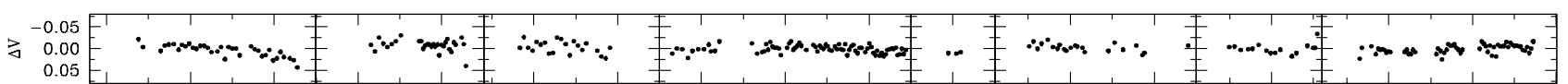

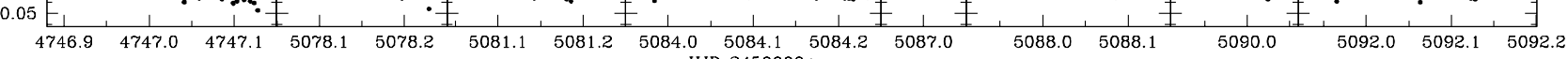
ID866 (NSV 25137)

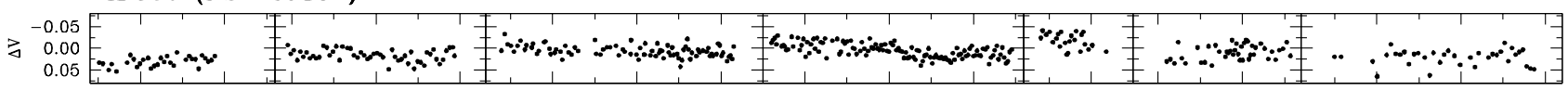

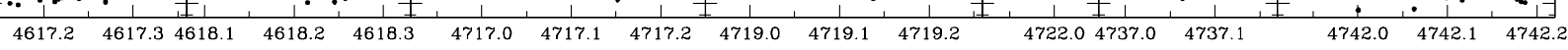

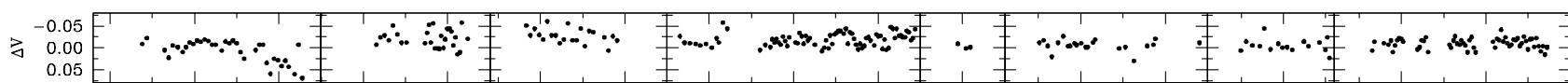

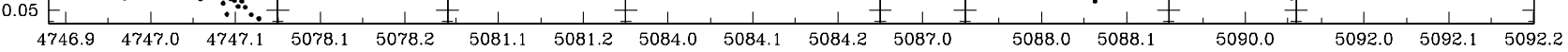

그림 9.-(계속).

ID2530 (V1380 Cyg)

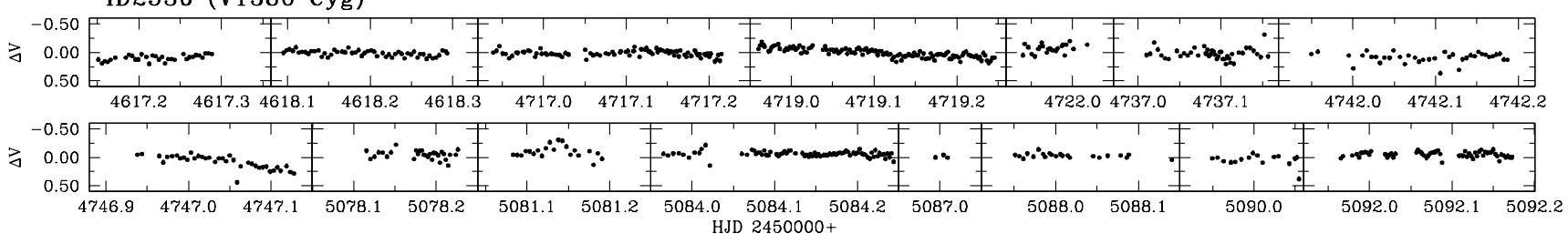

그림 9.-(계속). 